\title{
Assessing energy saving potentials of office buildings based on adaptive thermal comfort using a tracking-based method
}

Article

Accepted Version

Creative Commons: Attribution-Noncommercial-No Derivative Works 4.0

Ming, R., Yu, W., Zhao, X., Liu, Y., Li, B., Essah, E. and Yao, R. (2020) Assessing energy saving potentials of office buildings based on adaptive thermal comfort using a trackingbased method. Energy and Buildings, 208. 109611. ISSN 0378-7788 doi: https://doi.org/10.1016/j.enbuild.2019.109611 Available at https://centaur.reading.ac.uk/88576/

It is advisable to refer to the publisher's version if you intend to cite from the work. See Guidance on citing.

To link to this article DOI: http://dx.doi.org/10.1016/j.enbuild.2019.109611

Publisher: Elsevier

All outputs in CentAUR are protected by Intellectual Property Rights law, including copyright law. Copyright and IPR is retained by the creators or other copyright holders. Terms and conditions for use of this material are defined in the End User Agreement.

www.reading.ac.uk/centaur 
Central Archive at the University of Reading

Reading's research outputs online 
Assessing energy saving potentials of office buildings based on adaptive thermal comfort using a tracking-based method

Ru Ming a,b, Wei Yu ${ }^{\text {a,b,*, }}$, Xuyuan Zhao ${ }^{\text {a,c }}$, Yuan Liu ${ }^{\text {a,b }}$, Baizhan Li a,b, Emmanuel Essah ${ }^{\text {d }}$, Runming Yao ${ }^{\text {a,b,d }}$

a Joint International Research Laboratory of Green Buildings and Built Environments (Ministry of Education), Chongqing University, Chongqing 400045,

China

b National Centre for International Research of Low-carbon and Green Buildings (Ministry of Science and Technology), Chongqing University, Chongqing 400045, China

c GD Midea Air-Conditioning Equipment Co., Ltd, China

d School of the Built Environment, University of Reading, Reading RG6 6DB, UK

${ }^{*}$ Corresponding author. Joint International Research Laboratory of Green Buildings and Built Environments, Ministry of Education, Chongqing University, 400045, China.

E-mail address: yuweixscq@126.com (W. Yu). 


\begin{abstract}
Occupants' thermal comfort and their adaptation behaviors are essential aspects of building design and energy operation. There is a growing need to better understand the impact of seasonal variation on occupants' dynamic thermal comfort which provides evidence for building energy flexible design and management. The aim of this study is to investigate the interaction between occupants' thermal sensation and adaptive behavior in office buildings. Such understanding can provide detailed adaptation rules of human behavior in dynamic office buildings and quantify energy demands. In this study, a framework of a tracking method is proposed, which combines data collection (continuous monitoring of environmental parameters and daily questionnaire surveys), time boundary division and data analysis. Using the tracking method, field surveys were carried out in three mixed-mode office buildings in Chongqing, China. The time-series data was analyzed based on the indoor operative temperature under free-running conditions and five seasonal periods are classified i.e. Latter Spring (LS), Early Cooling period (EC), Middle Cooling period (MC), Latter Cooling period (LC) and Early Autumn (EA). Results show that for the same outdoor temperatures in different seasons, occupants' clothing insulation varied, indicating that the occupants were more sensitive to environmental changes in EA than in LS, as well as in EC than in LC. The study that flexible energy operation based on the thermal comfort demand can achieve energy savings compared with fixed temperature.
\end{abstract}

Keywords: tracking method; dynamic thermal comfort; human behavior; office buildings; energy saving

\title{
1. Introduction
}

The global population is increasingly dependent on energy-intensive indoor climates [1, 2]. However, reducing building's energy consumption and improving the indoor environment thermal performance is one of the conflicting criteria[3]. Buildings consume up to $40 \%$ of the total energy used in developed countries[4], whereas it is anticipated that developing nations will likely consume more energy than advanced nations by 2020[5]. Almost half of the energy consumption in buildings relates to Heating, Ventilation, and Air Conditioning (HVAC) systems mostly used to achieve thermal comfort. The high consumption of energy in buildings remains a growing concern; hence, a comprehensive understanding of occupants' behavior and dynamic thermal comfort in an evolving dynamic environment $[6,7]$ is required to prevent an adverse impact on energy conservation.

Individual behavior has significant impact on the surrounding environment, influencing both thermal comfort and energy consumption. Results from our previous study on free-running residential buildings revealed that occupants' adaptive responses and behavior exhibit seasonal variation[8]. In buildings with mixed-mode ventilation, occupants not only adjust clothing insulation, open/close 
windows and use fans in transition seasons, but also control the air conditioning in the cooling season. Some field studies, carried out in Spain[9, 10], Brazil[11, 12], Australia[13] and China[14], investigated the thermal sensation in mixed-mode office buildings, and the general conclusion was that there are certain adaptive behaviors required to maintain thermal comfort.

Over the past 20 years, research on thermal comfort has developed from a lab-based steady state method to a dynamic one[15], while the latter method includes transverse and longitudinal field studies. In field studies, statistical methods were applied to establish empirical regression models for the relationship between indoor comfort temperature and outdoor temperature based on large-scale survey $[16,17]$. However, most studies employing transverse field studies ignored the personal thermal preferences and experiences, which limit the applicability and implementation of adaptive processes. Similar methods have been used to research adaptability for thermal comfort in China[18-20].

Some longitudinal surveys conducted on adaptive thermal comfort in offices generally follow the data collection and analysis approach of the European Smart Controls and Thermal Comfort (SCATs)[21]. The SCATs project was built around the concept of adaptive comfort theory, providing a method of reducing the building energy consumption. Apart from the SCATs project, several similar longitudinal studies have been reported in the literatures[22-26]. These include a study conducted in UK, to monitor building comfort and thermal control using a simulation algorithm for window-opening behavior. This was developed for a year's data. The resulting output showed that an adaptive algorithm can accurately represent human thermal comfort conditions and the building performance [22]. In addition, in Japan, a long-term field survey of six office buildings investigated respondents' adaptations to the indoor climate. The findings showed that buildings with more options for personal control tracked natural temperatures more closely[23]. Other longitudinal field studies have been conducted in different climates in China. For instance, an investigation of office buildings in Chongqing was carried out to predict the probability of occupants' adaptive actions with regard to personal and environmental characteristics[24]. A detailed analysis of thermal history and adaptation of a long-term field study (2013-2015) of two heating periods in Harbin reported that participants adapted to their thermal environments. In particular, it was observed that different levels of exposure affected the participants' thermal comfort[25]. Furthermore, an analysis of the driving mechanisms of thermal behavior and opinions demonstrated a strong link between occupants' behavior and thermal comfort in office buildings in the northern part of China. The study proposed that the active interaction of offices' internal environments with the outdoor environment will motivate further connections between occupants' thermal opinions and outdoor physical variables[26]. However, in most recent researches [11, 14, 27-32], there is a lack of explanation regarding the dynamic changing characteristics of a person's behavioral adaptability to environmental changes, while there is a growing need to better understand the impact of seasonal variation on occupants' dynamic thermal comfort and using large time scales may hide the dynamic process of thermal adaptation. Therefore, obtaining detailed information such as the occupant's response to seasonal changes in climate in a large-scale survey is very challenging. 
To fill the gap, this study is set-out to examine the interaction between occupants' thermal sensation and adaptive behavior in office buildings to explore more detailed adaptation rules of human behavior in dynamic office buildings and to quantify to what degree comfort needs affect energy use. In this paper, the research is set out to address the following objectives:

1) To propose a tracking method of acquiring spatial-and-time-dependent information on adaptive thermal comfort research.

2) To study the interaction between human behavior and thermal sensation over time, and to explore the detailed characteristics of human behavior in dynamic office environments.

3) To quantify the contribution of adaptive thermal comfort to energy savings.

\section{Methodology}

The proposed tracking method (as illustrated in Fig. 1) is a three-step process comprising data collection, time division, and data analysis. The respondents being tracked were the same, which allows for the analysis of changes in thermal sensation and human behavior over time. Compared with methods used by previous studies, this study combined the assessment of human-centered information with monitoring of thermal environmental parameters. The method used in this study was also designed to incorporate survey data from the same respondents regularly as well as dynamic information on thermal comfort. This ensures a shift from conventional approach of thermal environmental evaluation in a discrete time period to a system that considers a continuous period of time. The research presented in this paper focuses on how occupants adaptively react to thermal environment changes in cooling season as well as the seasons before and after, known as the transition season[33]. The same method proposed above is can also be applied to the heating seasons. 


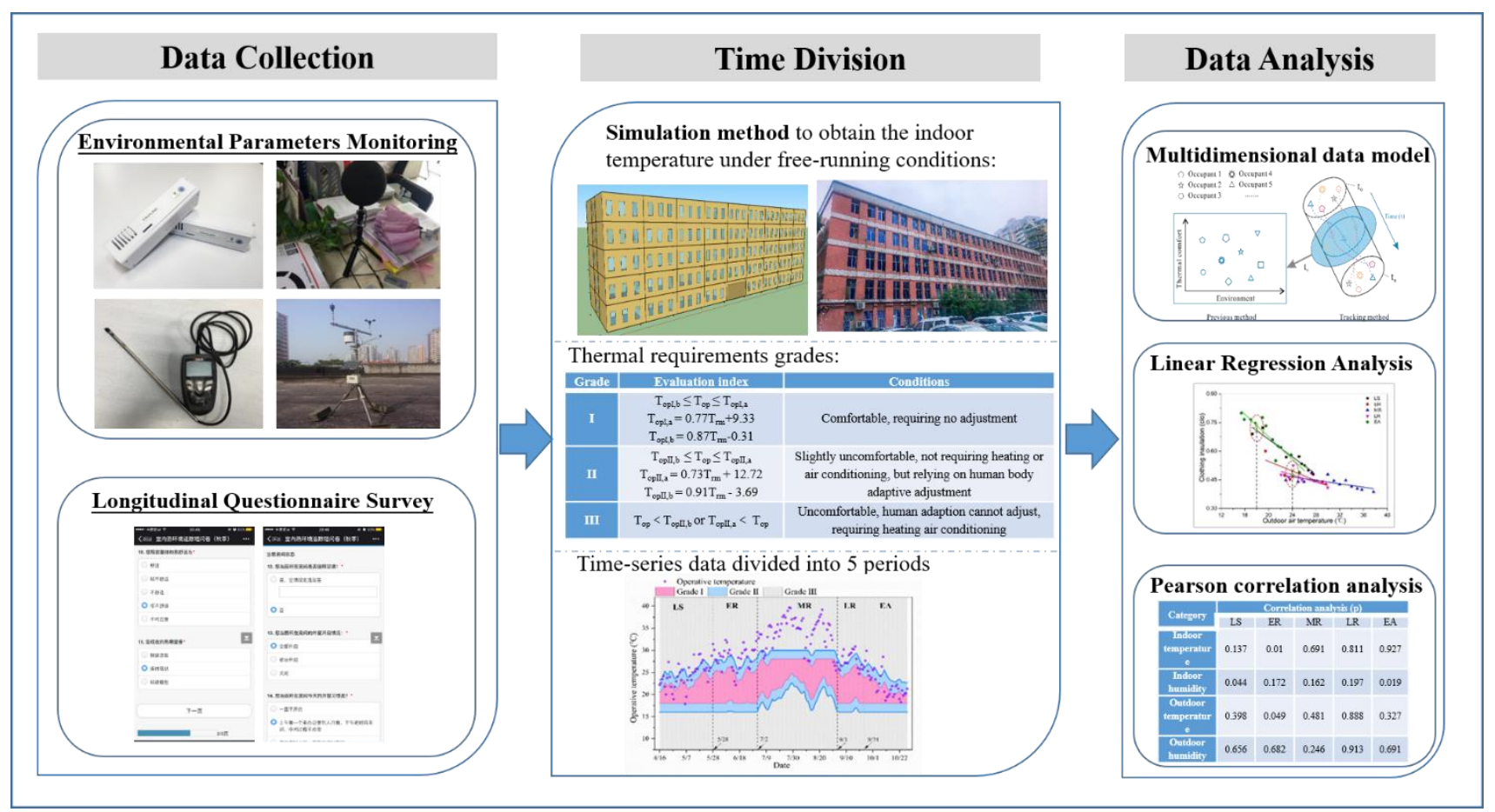

Fig.1. Proposed research methodology framework for capturing thermal comfort and behavior information

Real-time monitoring of environmental parameters and longitudinal questionnaire surveys in three multi-story office buildings in Chongqing, China (named A, B, and C in Fig. 2) were conducted to collect data. A total of six offices were selected at different floors and orientations in the three buildings. All selected options used a mixed-mode system with neither central heating nor cooling systems. However, the systems had single-unit air conditioning systems operating in cooling mode during summer. Onsite measurements lasted for nearly 7 months from April 16, 2017 to October 28, 2017, covering the partial transition season and the entire cooling season.

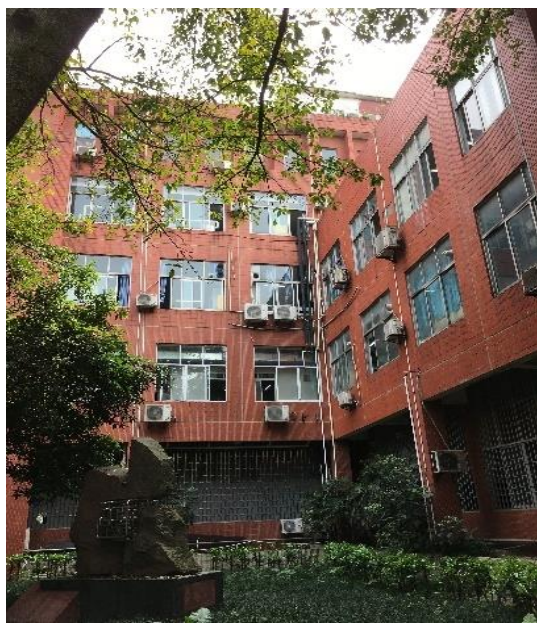

(a) Building A

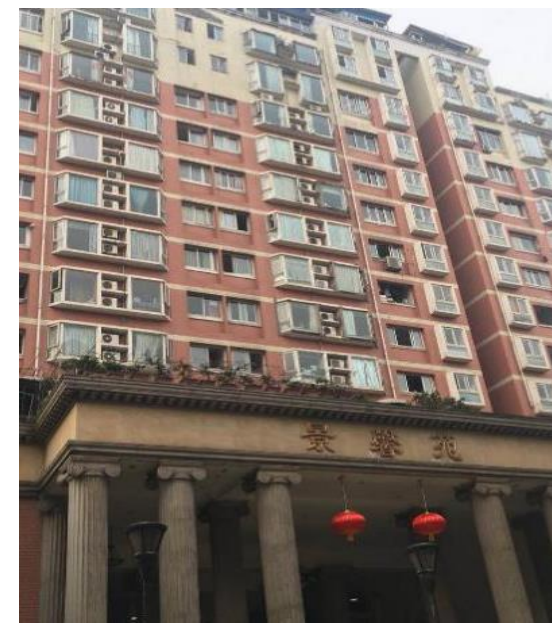

(b) Building B

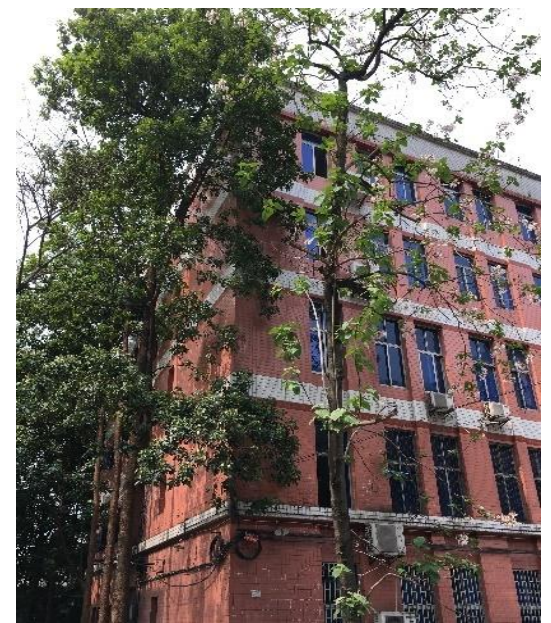

(c) Building $\mathrm{C}$

Fig.2. Three office buildings considered in this study

\subsection{Monitoring of physical and environmental parameters}


The monitoring system used in this study is shown in Fig. 3. The instruments used onsite were installed inside the offices to measure environmental parameters including the indoor air temperature, the relative humidity $(\mathrm{RH})$, and the globe temperature. According to[34], when the air velocity is below $0.20 \mathrm{~m} / \mathrm{s}$ and the metabolic rates are between 1.0met and 1.3met (not in direct sunlight), the operative temperature can be represented as the average of the indoor air temperature and the indoor main radiant temperature, as given in Equation (1):

$$
t_{o p}=\left(t_{a}+t_{r}\right) / 2
$$

where $t_{o p}$ is the indoor operative temperature, $t_{a}$ is the indoor air temperature, and $t_{r}$ is the mean radiant temperature, which can be assumed to be approximately equal to the globe temperature[35].

It's not our purpose to analyze the differences between different floors, so the surveys conducted in the middle floors of the three office buildings. A set of sensors was installed in each office with a total floor area of $<50 \mathrm{~m} 2$ and all measurement points were at least $0.6 \mathrm{~m}$ from an external wall to prevent the effects of direct sunlight in according with the measurement requirements by the American Society of Heating, Refrigerating and Air-Conditioning Engineers(ASHRAE)[36]. The layout of the offices and the position of the air-conditioning systems is demonstrated in Fig. 4. In order to minimize the interruption to the respondents, the monitoring instrument was placed in convenient locations to measure the microenvironment parameters. As shown in Fig. 4 (c), the measurement point was set at a height of $1.1 \mathrm{~m}$ above the floor which was just on the top of the partition to ensure that the air temperature and humidity readings were representative. Each sensor recorded and uploaded data every 5 minutes. The air velocity was not recorded continuously because of low interior air movement; therefore, these values were captured for a selected period of 2 days per week, which are considered as representative measurements. In this regard, measurements were taken over a 3-min duration to ensure data collected are representative of the environment considered. Outdoor environmental changes, including the air temperature and the relative humidity, were measured at a weather station located on the roof top of Building C, a 5-storey office building, which is close to the other buildings. As a result, the weather conditions do not vary significantly in the three buildings; thus, data collected would be applicable to the other monitoring sites. The monitoring sensors (illustrated in Fig. 4, the characteristics are listed in Table 1) were configured for real-time wireless data transmission to a cloud database, allowing researchers and respondents to monitor the indoor environment parameters using a computer or mobile APP terminals. To ensure that the working conditions of the test space were not altered, the real-life day to day working environment of the respondents was maintained. 


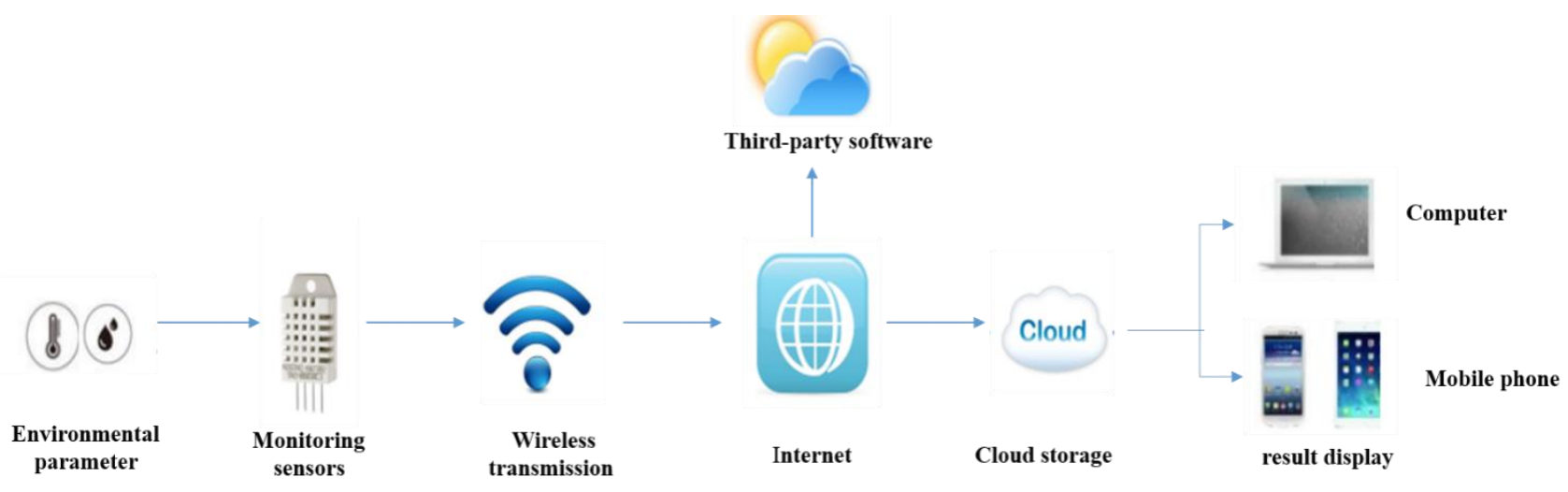

Fig.3. Schematic diagram of the monitoring system used in this study

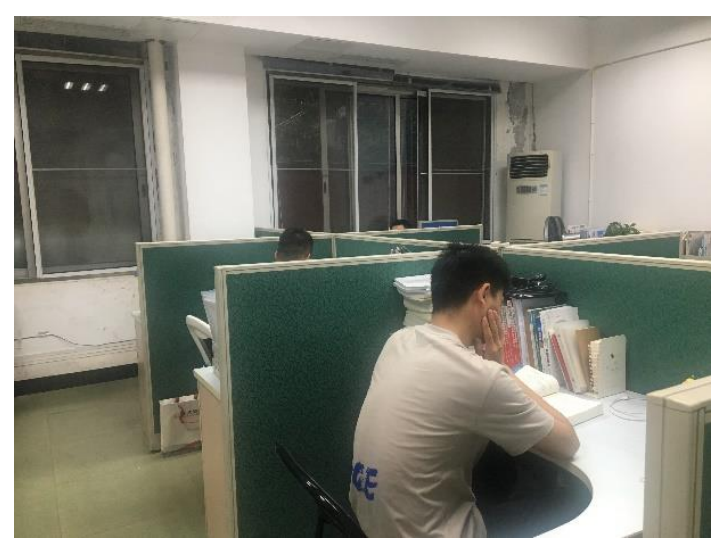

(a)

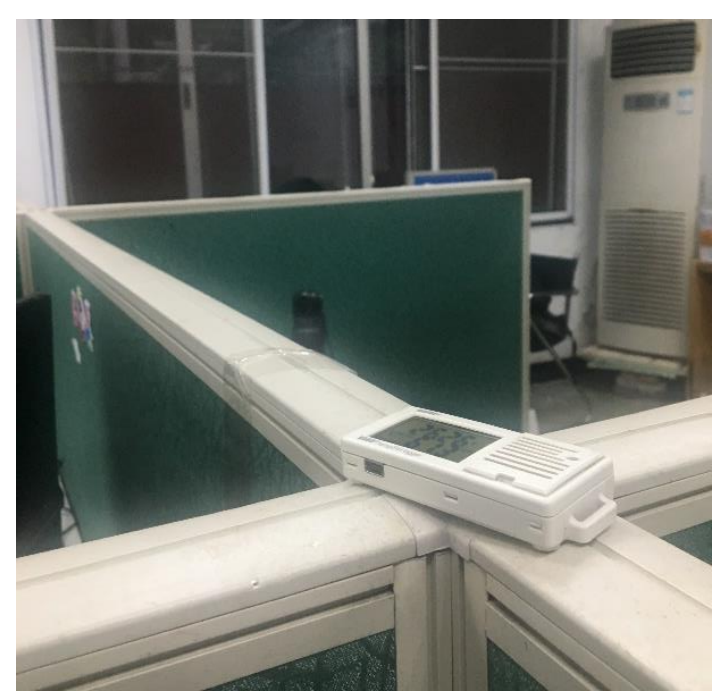

(c)

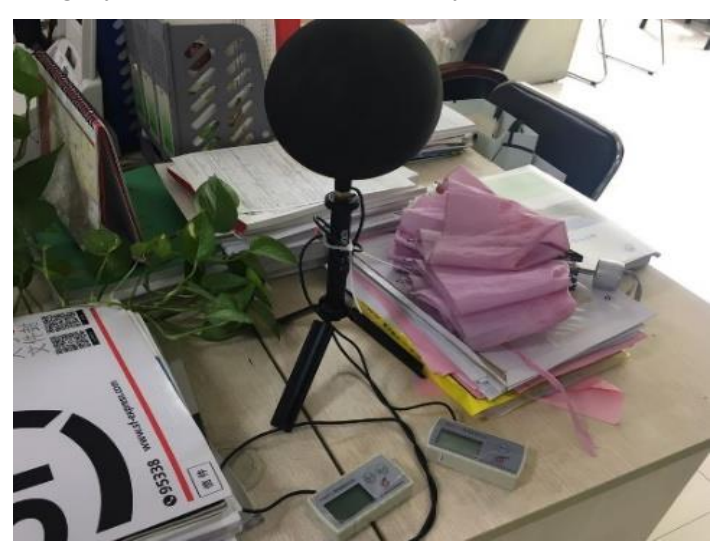

(b)

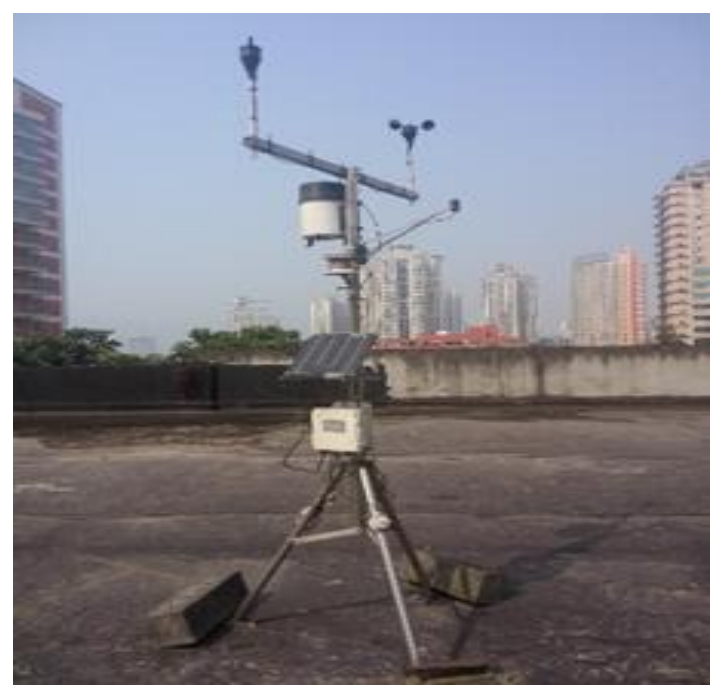

(d)

Fig.4. Layout of the offices and arrangement of the measurement points.

Table 1

Monitoring instrument specifications.

\begin{tabular}{ccccc}
\hline Name & Type & Parameter & Range & Accuracy \\
\hline \multirow{2}{*}{ Thermo-hygrometer } & ENVILINK & Indoor air temperature & $-40-125{ }^{\circ} \mathrm{C}$ & $\pm 0.25{ }^{\circ} \mathrm{C}$ \\
& & Indoor relative humidity & $0-99 \%$ & $\pm 2 \%$ \\
Globe thermometer & HWZY-1 & Indoor globe temperature & $-50-100{ }^{\circ} \mathrm{C}$ & $\pm 0.4{ }^{\circ} \mathrm{C}$
\end{tabular}


Hot-wire anemometer

Small outdoor weather station
VT110

U30-NRC
Indoor air velocity

Outdoor air temperature

Outdoor relative humidity
$0-3 \mathrm{~m} / \mathrm{s}$

$0.05 \mathrm{~m} / \mathrm{s} \pm 3 \%$

$-40-75^{\circ} \mathrm{C}$

$\pm 0.7^{\circ} \mathrm{C}$

$0-100 \%$

$\pm 3 \%$

\subsection{Longitudinal questionnaire survey}

The surveys were made available online during the survey period suing Wenjuan Xing software, an online questionnaire platform that can be accessed using phones or PCs. This platform dos not have a built-in function for repeating the same survey; WeChat (the most commonly used communication software in China) was used to send the survey links to the respondents at pre-specified daily times. To ensure the quality of the data, two questionnaire surveys were conducted for each respondent per week. This also ensured that there were no prevalent repetitions for which the respondents could be less engaging[37]. The expected completion time for each questionnaire was less than 5 mins to ensure that the questionnaire responses were not delayed due to the completion time.

Each survey covered background information, metabolic rate, thermal comfort and sensation, and adaptive behavior (clothing adjustment, window use, and A/C use) (Fig. 5). The thermal sensation options were aligned with the ASHRAE 7-point sensation scale and thermal expectations. The clothing insulation and metabolic rates were estimated in accordance with the Chinese code of "Evaluation standard for indoor thermal environment in civil buildings" [38]. In addition, the clothing insulation was increased by 0.03 clo for underwear, and 0.1 clo for standard office chairs as documented in [38]. During the measurement duration, respondents were allowed to adapt their clothing, window status, and/or air conditioning to reflect their real-life activities and notes were made at this time for subsequent analysis of behavioral adaptation to thermal environment changes. The option "the present status of the windows" was included in the questionnaire to reflect the 'at the time' situation. Before filling out the questionnaire, the respondents were informed that this option was considered to be window was opened, irrespective of whatever the windows were opened, with a small gap, or with a large gap, or fully opened. In the surveyed offices, each office has one air conditioning system and one controller embedded in it. There are multi-users in one office and they are all free to control the air conditioning system.

It has been suggested that this type of study should not have fewer than 20 respondents, and there has been productive studies with 30 respondents in a comparable study in Denmark[39].In this study, 29 respondents (15 males and 14 females) were selected. The age of the respondents was in the range of 23-44 years, and the respondents were all in good health. They have lived in the city for 2-17 years. Of the 1011 questionnaires disseminated to the respondents, a total 827 questionnaires $(81.8 \%)$ were completed and accepted, whereas 184 questionnaires were discarded for lack of completeness. 


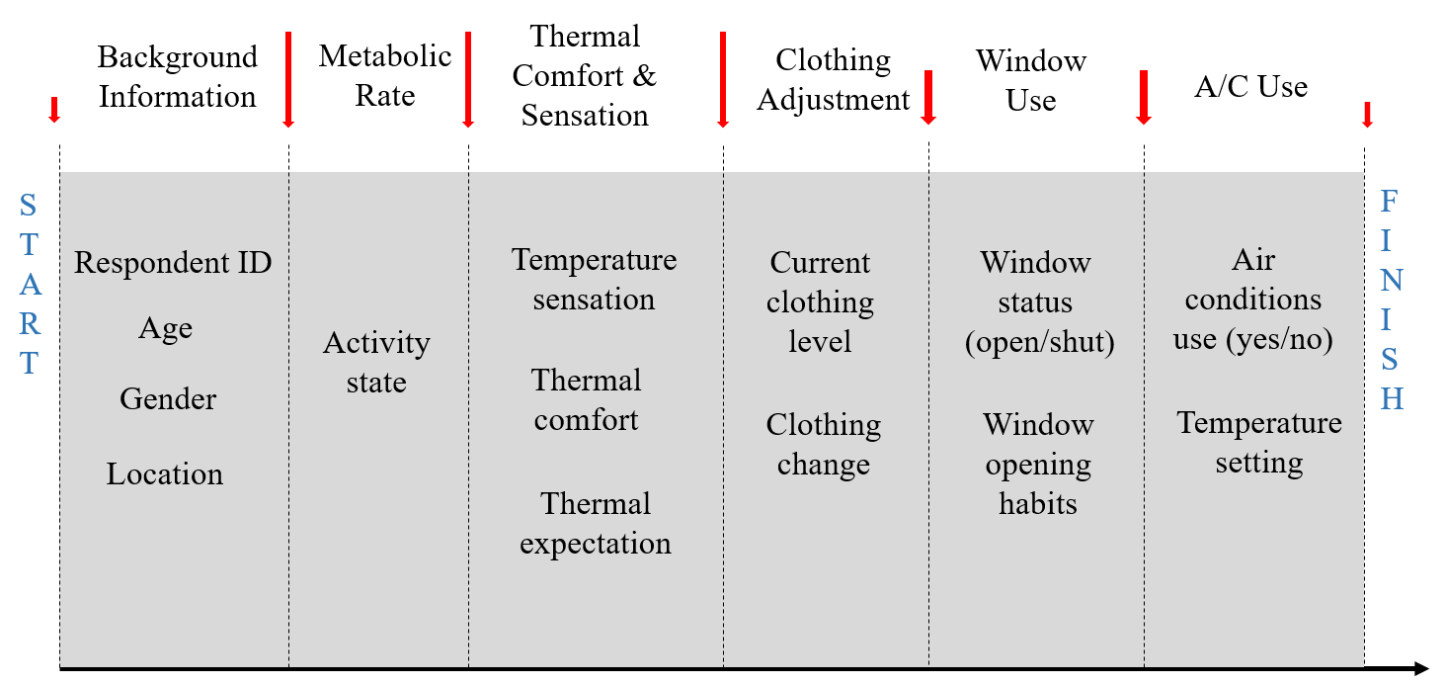

Fig.5. Question flow of online surveys

\subsection{Method for defining of time boundary}

Occupants have different thermal requirements in different periods according to their exposed environmental changes and variable adaptability. It is necessary to identify the distinct time boundaries in which occupants experience significant changes in terms of thermal sensation and behavior in order to characterize thermal comfort requirements and energy demand. For example, in northern China, the heating season is fixed on a certain starting date and an ending date according to the calendar [40]. This does not suit the residents in southern China, where air conditioning for heating and cooling are operated in an intermittent mode. An occupant's thermal sensation and adaptation behaviors are directly influenced by the indoor environment owing to the contribution of building systems such as envelope insulation. Therefore, the indoor operative temperature was used to identify the time boundaries. Because the mixed ventilation mode buildings were investigated in reality and the study was designed to ensure that occupants actively used climate-control measures during the survey period, "natural" (uncontrolled) room temperature could not be obtained from the investigation. In order to obtain the indoor operative temperature under free-running conditions, computer simulations were carried out using EnergyPlus software for the surveyed offices based on the Chinese code "JGJ672006" [40].

In this study, Building $\mathrm{C}$ was selected for the simulation as shown in Fig. 6. There are 18 rooms on each floor with an area of $1054 \mathrm{~m} 2$. The Window to Wall Ratio (WWR) is 0.4 . The boundary conditions and required information needed for thermal modeling were obtained from the actual parameters of Building C, as presented in Table 2. 


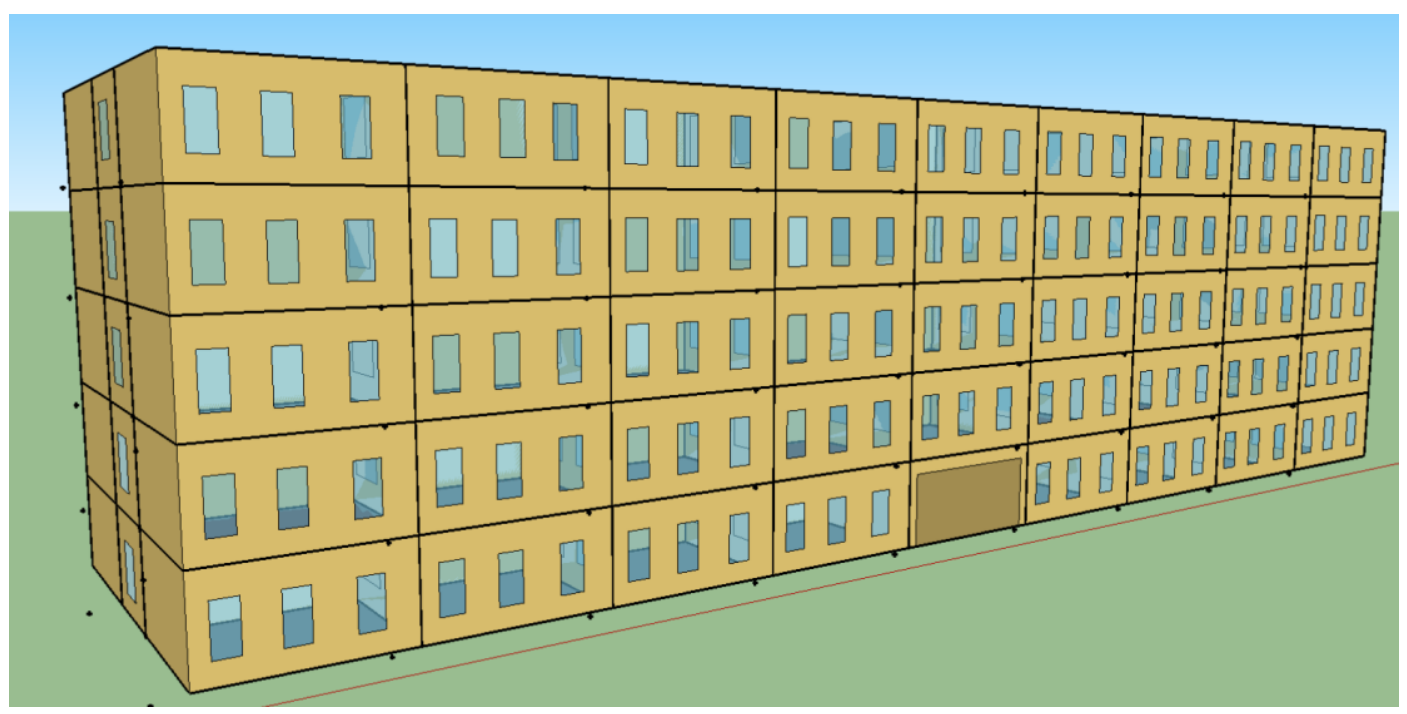

(a) The simulation model based on Building $\mathrm{C}$

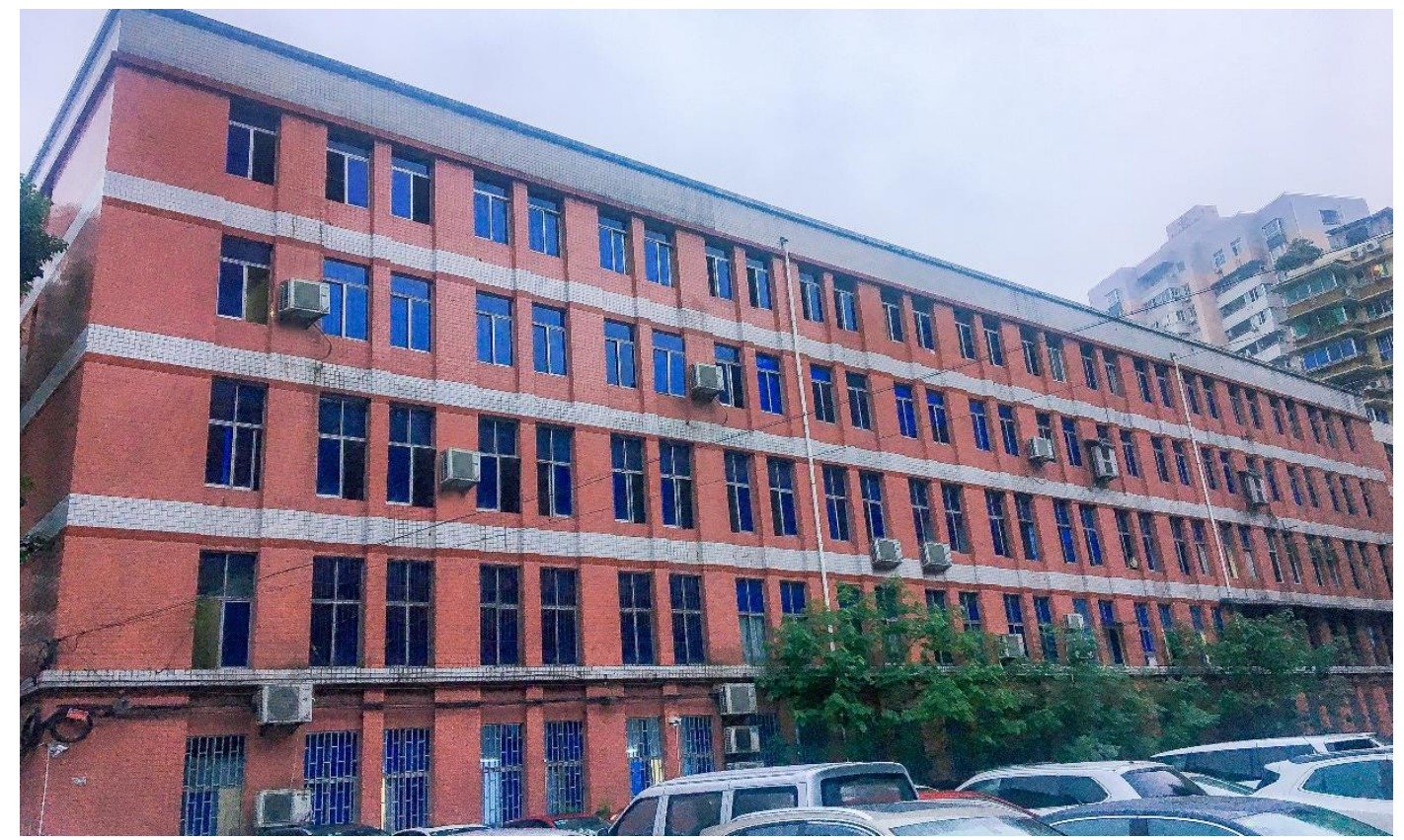

(b) The layout of Building $\mathrm{C}$

Fig. 6. The simulation model and layout of Building C.

Table 2

Summary of design conditions used for creating thermal models and envelope characteristics for the base configurations.

\begin{tabular}{|c|c|c|c|}
\hline \multicolumn{2}{|c|}{ Construction } & Unit & Value \\
\hline \multirow{4}{*}{$\begin{array}{c}\text { Envelope thermal } \\
\text { characteristics }\end{array}$} & Walls & U-values $\left(\mathrm{Wm}^{-2} \mathrm{~K}^{-1}\right)$ & 0.83 \\
\hline & \multirow{2}{*}{ Windows } & U-values $\left(\mathrm{Wm}^{-2} \mathrm{~K}^{-1}\right)$ & 2.8 \\
\hline & & Solar Heat Gain Coefficient & 0.75 \\
\hline & Floors & U-values $\left(\mathrm{Wm}^{-2} \mathrm{~K}^{-1}\right)$ & 0.48 \\
\hline \multirow{2}{*}{ Internal loads } & Occupant density & $\mathrm{m}^{2} / \mathrm{p}$ & 10.0 \\
\hline & Lighting density & $\mathrm{W} / \mathrm{m}^{2}$ & 9.0 \\
\hline
\end{tabular}




\begin{tabular}{l|l|c|c}
\hline & Equipment density & $\mathrm{W} / \mathrm{m}^{2}$ & 15.0 \\
\hline
\end{tabular}

The average outdoor temperatures and the average indoor operative temperature of the middle floor under free-running conditions from simulated data were obtained using weather data for the typical meteorological year in Chongqing as a reference.

Two dimensionless error indexes, namely the Mean Bias Error (MBE) and Coefficient of Variation of the Root Mean Square Error (CV(RMSE)), were used to validate the simulation model based on the data obtained from April 16 to May 28, 2017, in Building C. The MBE and CV(RMSE) were calculated using Equation 2 and Equation 3, respectively.

$$
\begin{gathered}
\mathrm{MBE}=\frac{\sum_{i=1}^{N_{i}}\left(M_{i}-S_{i}\right)}{\sum_{i=1}^{N_{i}} M_{i}} \\
\mathrm{CV}(\mathrm{RMSE})=\frac{\sqrt{\sum_{i=1}^{N_{i}}\left[\frac{\left(M_{i}-S_{i}\right)^{2}}{N_{i}}\right]}}{\frac{1}{N_{i}} \sum_{i=1}^{N_{i}} M_{i}}
\end{gathered}
$$

where, $M_{i}$ is the measured value corresponding to time $\mathrm{i}\left({ }^{\circ} \mathrm{C}\right) ; S_{i}$ is the simulated value corresponding to time $\mathrm{i}\left({ }^{\circ} \mathrm{C}\right)$; and $N_{i}$ is the total number of values used in the calculation.

Table 3 lists the hourly simulated and measured results of MBE and CV(RMSE) for the indoor air temperature and the indoor operative temperature. It can be observed that the MBE values are within $-5 \%$, and the CV(RMSE) values are less than $10 \%$. This indicates satisfactory application of the model used in this study[41].

Table 3

Simulation and measurement results of MBE and CV(RMSE).

\begin{tabular}{ccc}
\hline Item & MBE & CV(RMSE) \\
\hline Indoor air temperature & $-4.09 \%$ & $9.27 \%$ \\
Indoor operative temperature & $-4.54 \%$ & $9.43 \%$ \\
\hline
\end{tabular}

The running mean of the outdoor temperature $\left(T_{\mathrm{rm}},{ }^{\circ} \mathrm{C}\right)$ is calculated as given in Equation 4 , based on 7-day weighted temperatures prior to the day used for the calculation [42].

$$
\mathrm{T}_{\mathrm{rm}}=\left(\mathrm{T}_{\text {ed-1 }}+0.8 \mathrm{~T}_{\text {ed-2 }}+0.6 \mathrm{~T}_{\text {ed-3 }}+0.5 \mathrm{~T}_{\text {ed- } 4}+0.4 \mathrm{~T}_{\text {ed- }-5}+0.3 \mathrm{~T}_{\text {ed- } 6}+0.2 \mathrm{~T}_{\text {ed- }-7}\right) / 3.8
$$

where $T_{r m}$ is the running mean temperature based on the previous 7-day weighted temperatures $\left({ }^{\circ} \mathrm{C}\right)$ and $T_{e d-n}$ is the daily mean outdoor air temperature for $\mathrm{n}$-days prior to the day used for the calculation $\left({ }^{\circ} \mathrm{C}\right)$.

The indoor and outdoor thermal environments were then classified into three grades (I, II, and III) based on the output in accordance with the Chinese code "GB/T 50785-2012" (Table 4) [38]. Grade I represents the environment in which $90 \%$ of the occupants achieved thermal satisfaction ($0.5 \leq \mathrm{APMV} \leq 0.5$ ). Grade II represents the environment in which $75 \%$ of the occupants achieved thermal satisfaction $(-1 \leq \mathrm{APMV}<-0.5$ or $0.5<\mathrm{APMV} \leq 1)$. Grade III represents the environment in 
which less than $75 \%$ of the occupants achieved thermal satisfaction (APMV $<-1$ or APMV $>1$ ). Details of the classifications are illustrated in Table 4.

\section{Table 4}

Classifications for indoor operative temperature $\left(T_{o p},{ }^{\circ} \mathrm{C}\right)$ comfort level based on Chinese code "GB/T 50785-2012" [38].

\begin{tabular}{ccc}
\hline Grade & Evaluation index & Conditions \\
\hline & $T_{\mathrm{opI}, \mathrm{b}}{ }^{* *} \leq T_{\mathrm{op}} \leq T_{\mathrm{opl}, \mathrm{a}}{ }^{*}$ & \\
I & $T_{\mathrm{opl}, \mathrm{a}}{ }^{*}=0.77 T_{\mathrm{rm}}+9.33$ & Comfortable, requiring no adjustment \\
& $T_{\mathrm{opl}, \mathrm{b}}{ }^{* *}=0.87 T_{\mathrm{rm}-}-0.31$ & \\
& $T_{\mathrm{opII}, \mathrm{b}}{ }^{* *} \leq T_{\mathrm{op}} \leq T_{\mathrm{opII}, \mathrm{a}}{ }^{*}$ & Slightly uncomfortable, heating or air conditioning not required, \\
II & $T_{\mathrm{opII}, \mathrm{a}}{ }^{*}=0.73 T_{\mathrm{rm}}+12.72$ & relying on human body adaptive adjustment \\
& $T_{\mathrm{opII,b},}{ }^{* *}=0.91 T_{\mathrm{rm}-3.69}$ & Uncomfortable, human body adjustment not sufficient heating or \\
III & $T_{\mathrm{op}}<T_{\mathrm{opII}, \mathrm{b}}{ }^{* *}$ or $T_{\mathrm{opII}, \mathrm{a}}{ }^{*}<T_{\mathrm{op}}$ & air conditioning required \\
\hline
\end{tabular}

* $T_{\mathrm{op}, \mathrm{a}}$ and $T_{\mathrm{opII}, \mathrm{a}}$ represent the upper limit of thermal comfort grade I and grade II, respectively.

** $T_{\mathrm{op}, \mathrm{b}}$ and $T_{\mathrm{opII}, \mathrm{b}}$ represent the lower limit of thermal comfort grade I and grade II, respectively.

\subsection{Data analysis}

In order to extract detailed information regarding human adaptation to thermal comfort, a multidimensional data model was developed and categorized into (1) thermal environmental parameters, (2) correlation parameters for human thermal comfort, and (3) time to collect human thermal comfort multi-dimensional tracking data. This provided a three-dimensional data stream (Fig. 7) which was used for further analysis of adaptive thermal comfort behaviors.

Data collected from environmental monitoring and surveys were compared and analyzed using linear regression to fit the relationship between the clothing insulation and the outdoor air temperature, and between the thermal sensation vote and the indoor air temperature. The determination coefficient $\mathrm{R}^{2}$ was used to indicate the goodness of fit. Pearson correlation analysis was then used to evaluate the relevance between the proportion of window-opening frequency and environmental parameters. Statistical analysis was performed using SPSS 25.0 software and significance level of $\mathrm{p}=0.05$ was obtained. 


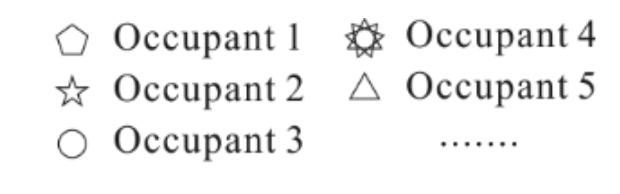

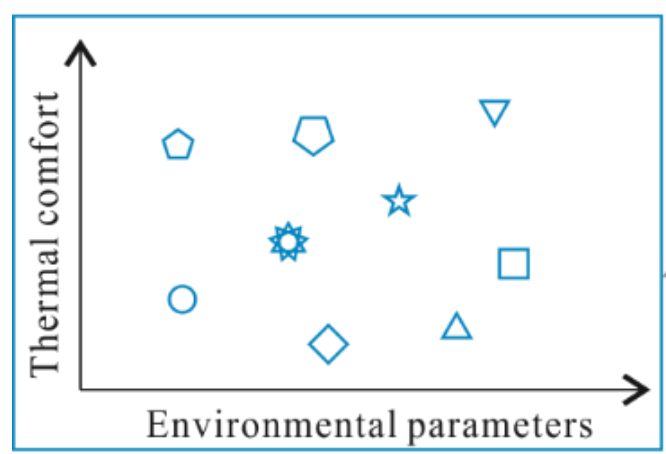

Previous method

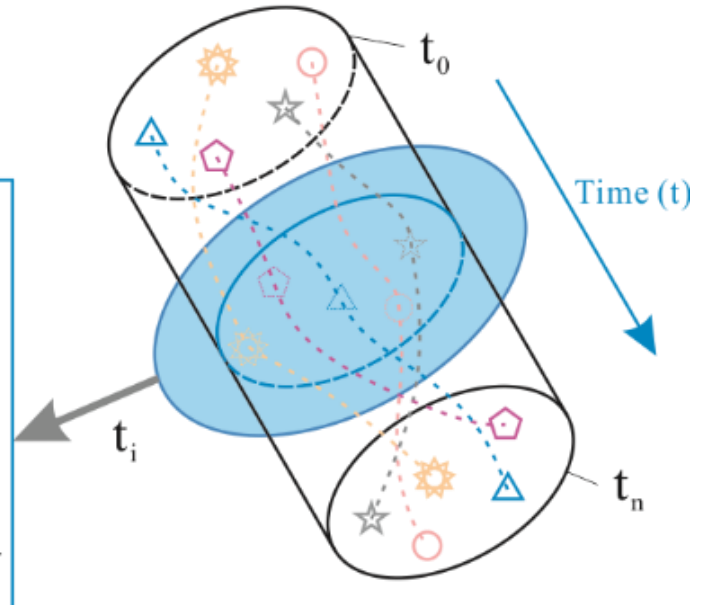

Tracking method

Fig. 7. Model of a three-dimensional data stream, used to differentiate human thermal tracking data.

\section{Results and analysis}

\subsection{Time division}

To further determine the time division, the boundary of the indoor thermal environment evaluation grades was calculated based on Table 4. As shown in Fig. 8, the range enclosed by the red area is Grade I. The range represented by the blue area is Grade II. The area beyond Grade I and Grade II is grade III. Temporal patterns in the natural thermal environment allowed the division of the research period into distinct stages (Fig. 8). From April 16 to May 27, and September 24 to October 28, the indoor thermal environment was mostly Grade II (adjustment-free); the former period was defined as Late Spring (LS) and the latter as Early Autumn (EA). From May 28 to July 1, the indoor thermal environment varied between grades II and III, indicating that temperature regulation was required; this was defined as the Early Cooling period (EC). From July 2 to September 2, over $90 \%$ of the indoor temperatures were grade III; this was defined as the Middle Cooling period (MC). From September 3 to 23, the indoor thermal environment fluctuated between grades II and III; this was defined as the Late Cooling period (LC). 


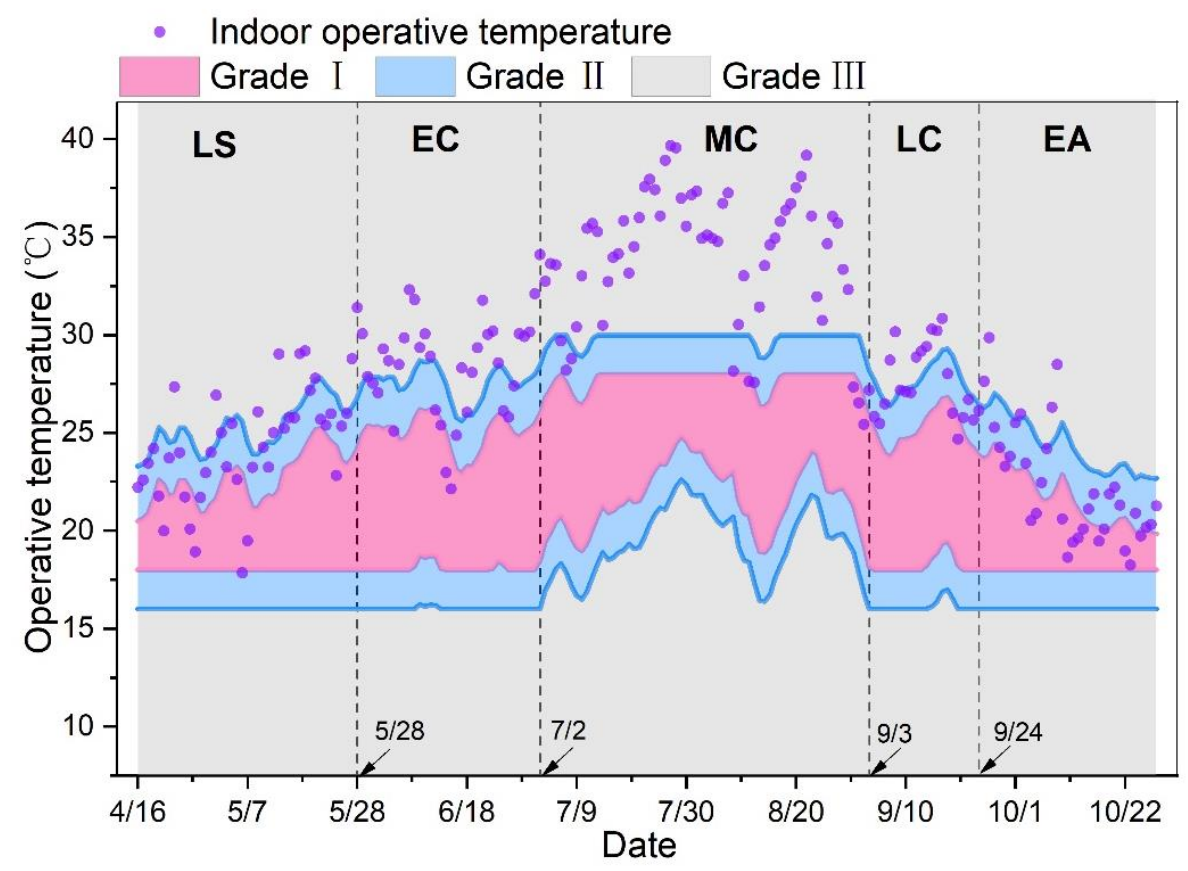

Fig. 8. Daily indoor operative temperature under natural ventilation environment (purple dots) in the modelled building calculated using outdoor temperature data. The regions in red, blue, and gray represent the three categories defined in Table 3. The study period is divided into five periods: Late Spring (LS), Early Cooling (EC), Middle Cooling (MC), Late Cooling (LC), and Early Autumn (EA).

\subsection{Thermal environment}

The monitoring instruments continuously recorded the physical and environmental parameters during the entire study period. The daily fluctuations of the indoor and outdoor environmental parameters that directly affected the respondents' thermal perceptions are shown in Fig. 9. The results reflect the average distribution of the three buildings. The radiant temperature was calculated using the globe temperature, air temperature, and air velocity[36]. From Fig. 9, it can be observed that the daily outdoor average air temperature varied from $15.0^{\circ} \mathrm{C}$ in $\operatorname{LS}$ (May 6, 2017) to $37.2^{\circ} \mathrm{C}$ in MC (August 22, 2017). The trend of the daily average indoor air temperature is similar to that of the indoor radiant temperature; thus, the former was used to evaluate the indoor environment[43]. In addition, this was quite stable during the cooling season (approximately $25^{\circ} \mathrm{C}$ ), but lower in LS and EA. The daily average outdoor relative humidity showed high levels of fluctuations in the rang off 41.5-97.0\%. However, the indoor relative humidity varied slightly, with mean values of $51.9 \%, 60.6 \%, 52.8 \%$, $55.9 \%, 59.6 \%$ for each period, respectively. Overall, the data indicate significant regulation of the indoor thermal environment. 

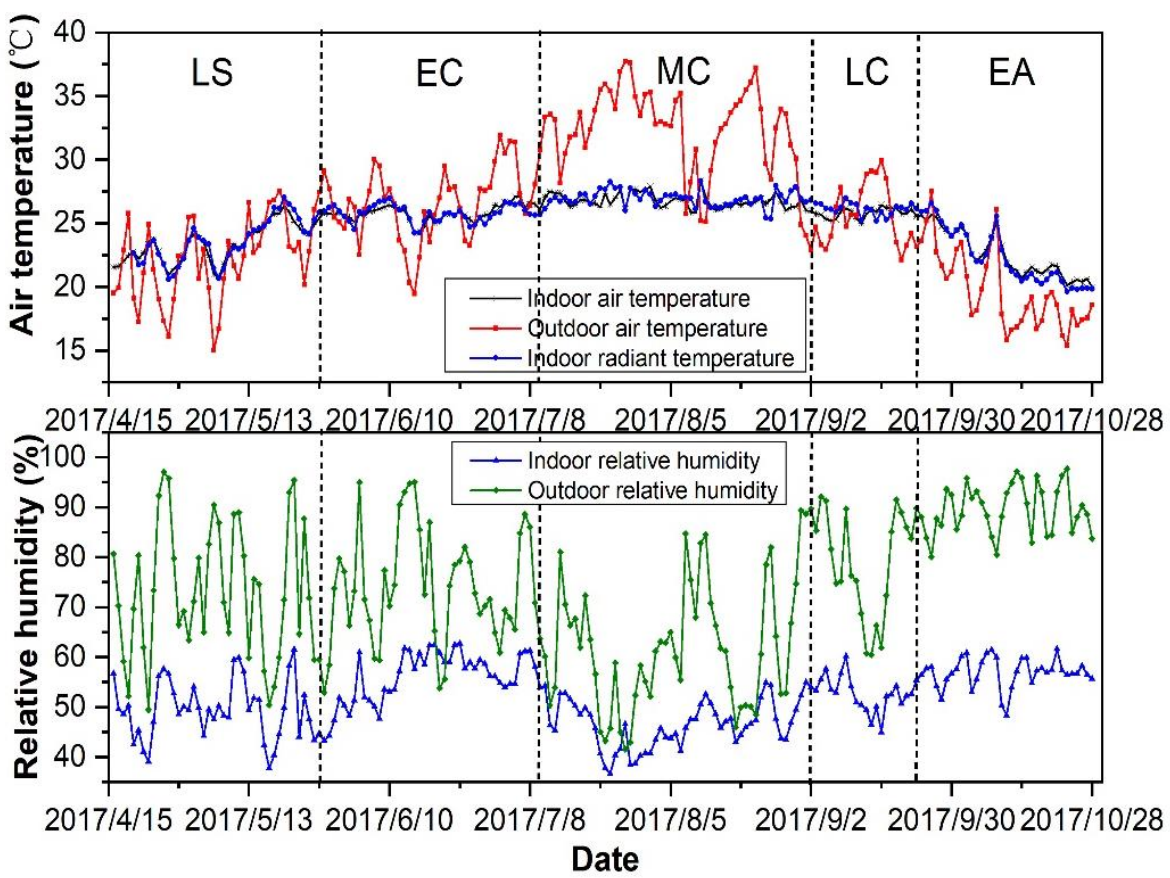

Fig. 9. Daily fluctuations in indoor and outdoor temperature and relative humidity

\subsection{Thermal sensation vote}

Although various indices can be used to quantitatively describe the respondents' subjective thermal perceptions[44], the Thermal Sensation Vote (TSV) can serve as a representative indicator for general thermal comfort assessment, whereas the Predicted Mean Vote (PMV) is suitable for evaluating artificial environments[45]. However, a suitable assessment index for mixed-mode buildings has not been reported. In this study, the Adaptive Predicted Mean Vote (aPMV) was used to predict the occupancy's thermal comfort[46]. This model has been adopted by the current Chinese standard 'Evaluation Standard for Indoor Thermal Environments in Civil Buildings GB/T50785-2012'.

The aPMV can be calculated using the following equation:

$$
a P M V=\mathrm{PMV} /(1+\lambda \times \mathrm{PMV})
$$

where, $\lambda$ is the "adaptive coefficient". For office buildings, the values of $\lambda$ in the HSCW zone are 0.21 under warm conditions, and -0.49 under cool conditions, as described in the standard in [38].

The TSV values were obtained based on responses from the respondents to the thermal sensation scale in the surveys (Fig. 10). This indicated that the thermal sensations of the respondents were within the comfort range and close to thermoneutrality. In the LS period, the TSV was close to neutral, whereas in the other periods it was slightly cool (although this is still acceptable). The TSV was lowest in $\mathrm{MC}$ as respondents had lower clothing insulation values and the indoor air temperature was maintained at a lower level when the questionnaire was completed. In particular, there was an abrupt 
thermal sensation around August 20 which was significantly lower than neutral. It can be observed from Fig. 9 that there was a marked reduction in the outdoor temperature around August 20 because the respondents provided low thermal sensation votes.

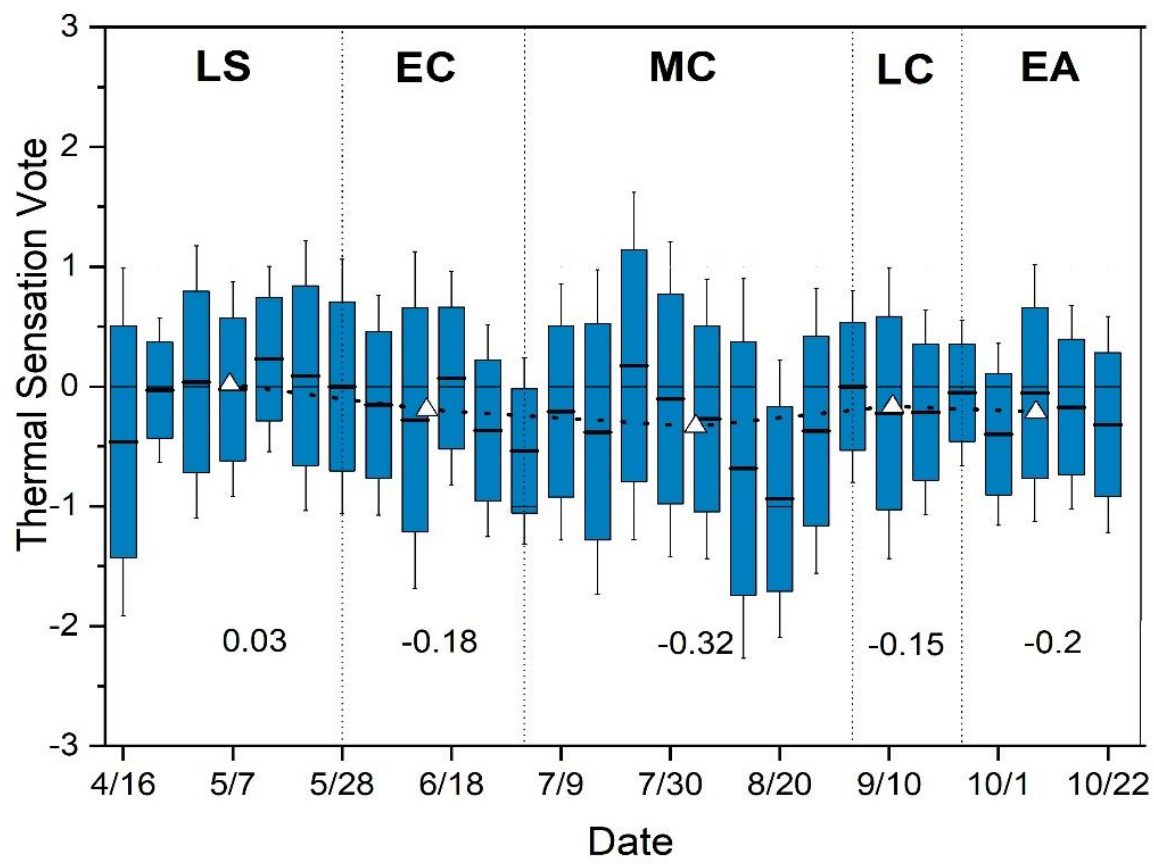

Fig. 10. Distribution of respondents' thermal sensation votes. Triangles indicate mean by period (values given below)

Fig. 11 showed the comparisons of TSV and aPMV in terms of indoor operative temperature in each period. Statistical regression equations for TSV and the indoor operative temperature in each period were illustrated in Table 5. As shown in Fig. 11, the values of aPMV were close to TSV in each period, demonstrating that the aPMV model performed quite well in the cooling season and transition season using the value indicated in the GB/T50785-2012. Therefore, the dynamic thermal comfort evaluation method should be adopted in mixed-mode buildings in order to consider the adaptability of the occupants.
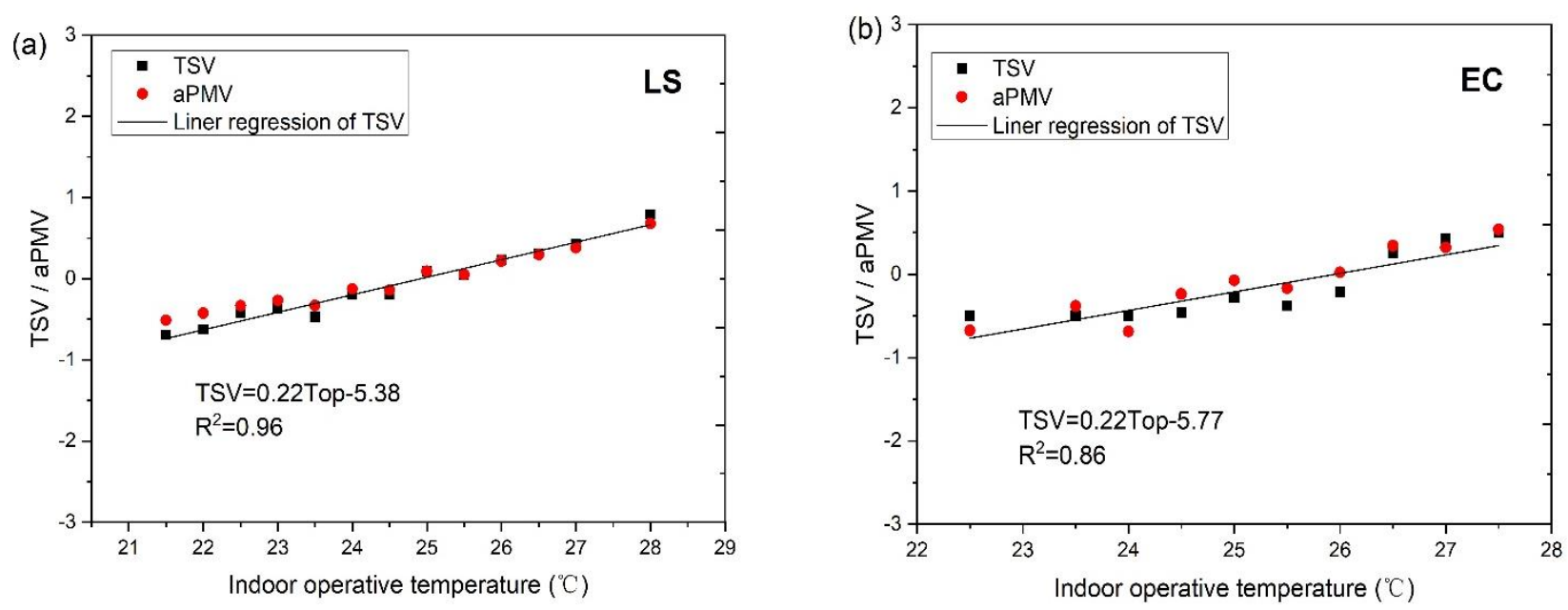

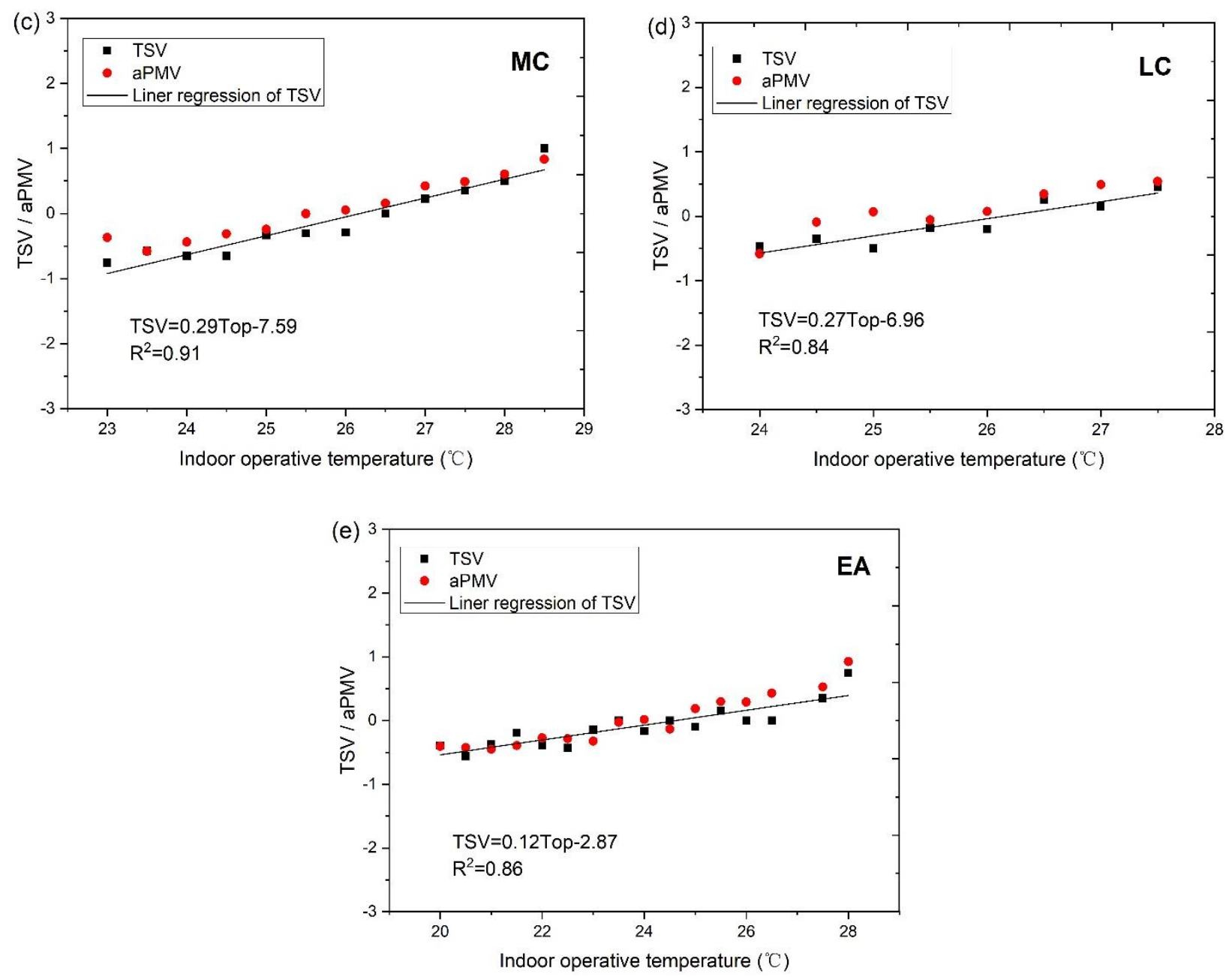

Fig. 11. Comparison of TAV and aPMV in each period, (a)-LS, (b)-EC, (c)-MC, (d)-LC, and (e)-EA Table 5

Liner regression formulas for TSV in each period.

\begin{tabular}{clc}
\hline Period & Regression Formulas & $R^{2}$ \\
\hline LS & $T S V=0.22 T_{\mathrm{op}}-5.38$ & 0.96 \\
EC & $T S V=0.22 T_{\mathrm{op}}-5.77$ & 0.86 \\
MC & $T S V=0.29 T_{\mathrm{op}}-7.59$ & 0.91 \\
LC & $T S V=0.27 T_{\mathrm{op}}-6.96$ & 0.84 \\
EA & $T S V=0.12 T_{\mathrm{op}}-2.87$ & 0.86 \\
\hline
\end{tabular}

\subsection{Thermal adaption}

\subsubsection{Clothing adjustment}

In the study by Lu et al.[48], altering the clothing levels is a typical adaptive method that has significant impact on thermal comfort[47]. This is because clothing insulation can be linearly related to the outdoor temperature when the latter changes within a certain range[43]. From the linear regression curves in Fig.12, the research established the average clothing insulation dependence on 
outdoor air temperature in different periods (Fig. 12, Table 6). The clothing insulation by period is in the ranged of $0.43-0.72$ with a mean value of 0.54 (see Table 6).

Table 6

Regression formulas for clothing insulation in each period.

\begin{tabular}{cccc}
\hline Period & $\begin{array}{c}\text { Mean Value of Clo in } \\
\text { each period }\end{array}$ & Regression Formulas & $R^{2}$ \\
\hline Whole Period & 0.54 & $I_{\text {clo }}=0.001 T_{\text {out }}{ }^{2}-0.072 T_{\text {out }}+1.69$ & 0.96 \\
LS & 0.59 & $I_{\text {clo }}=-0.023 T_{\text {out }}+1.122$ & 0.91 \\
EC & 0.47 & $I_{\text {clo }}=-0.013 T_{\text {out }}+0.798$ & 0.67 \\
MC & 0.43 & $I_{c l o}=-0.005 T_{\text {out }}+0.574$ & 0.61 \\
LC & 0.47 & $I_{c l o}=-0.009 T_{\text {out }}+0.701$ & 0.41 \\
EA & 0.72 & $I_{c l o}=-0.029 T_{\text {out }}+1.262$ & 0.85 \\
\hline
\end{tabular}

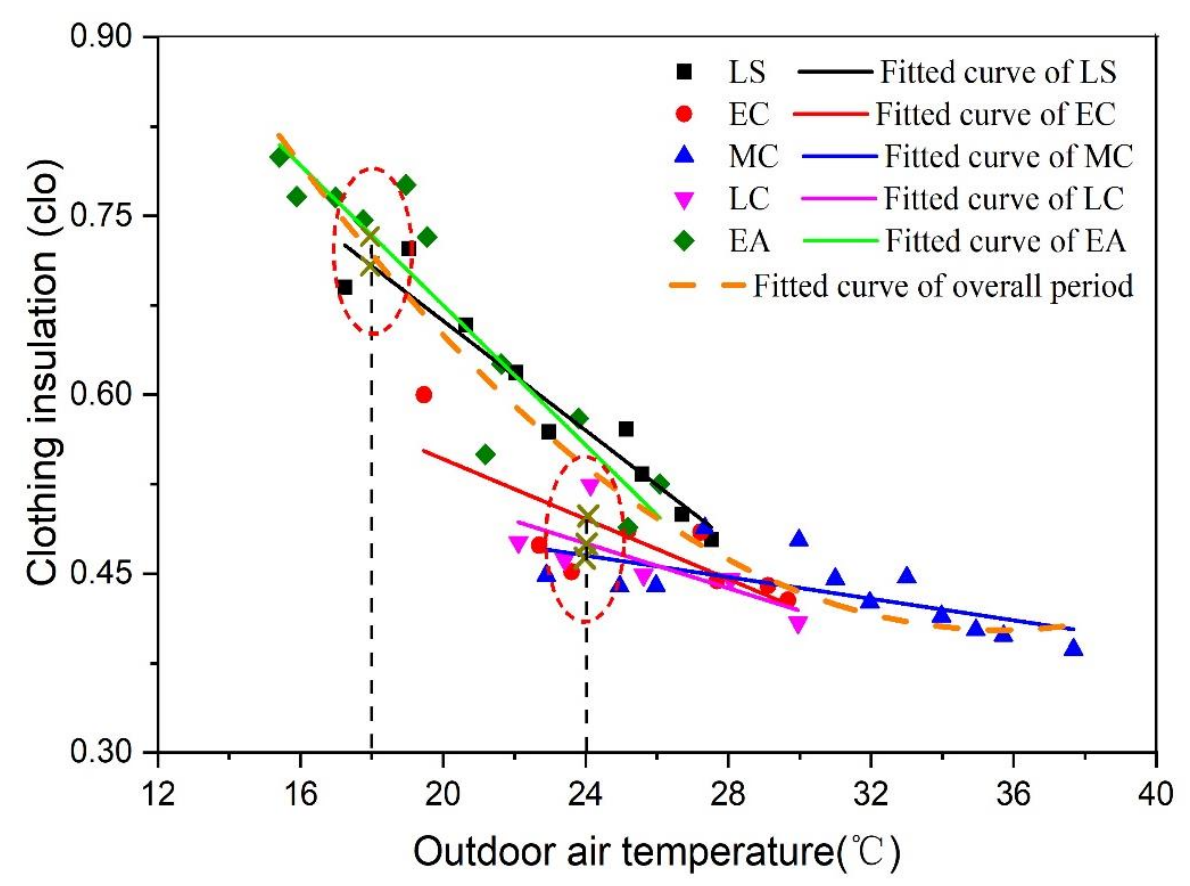

Fig. 12. Statistical regression of clothing insulation in each period.

Clothing insulation in different periods varied, despite similar outdoor temperature conditions. For instance, at an outdoor air temperature of $18.0^{\circ} \mathrm{C}$, the clothing insulation values were 0.71 clo in $\mathrm{LS}$ and 0.74 clo in EA. The slope of EA was steeper than that of LS, indicating that the respondents are more sensitive to changes in the outdoor thermal environment in EA and are thus more sensitive to cold.

During the refrigeration period, clothing insulation was low with minimal changes, but the adaptability still differed under the same outdoor temperature. For example, at $24.0^{\circ} \mathrm{C}$, the steepness of the regression curves was $\mathrm{EC}>\mathrm{LC}>\mathrm{MC}$, reflecting differing levels of sensitivity and clothing effectiveness in varying thermal comfort. During the full cooling period, the clothing insulation value 
changed the least, but the effect of clothing insulation on adaptive thermal comfort declined.

EC and MC reached the same clothing insulation value at an outdoor air temperature of $27.8^{\circ} \mathrm{C}$, whereas LC and $\mathrm{MC}$ achieved this value at $26.1^{\circ} \mathrm{C}$. Compared with $\mathrm{LC}$, respondents in EC were more sensitive to changes in outdoor air temperature and were more likely to adapt though clothing adjustment. After the period of MC, long-term dependence on air-conditioning would limit occupants' adaptability, leading to reduction in the regulation of clothing insulation. Therefore, the coefficient $\mathrm{R}^{2}$ related to the regression in LC was just 0.41 after being in an air-conditioned environment for a long time. Once the temperature reached $27.8{ }^{\circ} \mathrm{C}$, clothing insulation stabilized, and clothing adjustment became less important or effective. This suggests that, in EC, respondents experienced a change from a cold to a warm environment undergoing psychological effects that influenced their behavior.

\subsubsection{Window-opening adjustment}

The frequency of window-opening is defined as the ratio of the number of rooms with opened windows to the total number of the survey rooms at one time period. The proportion of respondents indicated that windows were "open during working hours" was highest in four of the five periods, up to $80 \%$ in LS and EA, but declined in MC. To date, window adjustments have been used as the main adaptive control in indoor and personal environments[48]. However, from Fig. 13, the option of "Never open" a window followed the opposite influencing pattern, noted to be highest in MC and lower in either direction. Although the proportion of "always open" was generally lower, it was higher in MC than in EC or LC, possibly because the use of air conditioning systems resulted in lack of fresh air such that some respondents opened windows for ventilation. Only a small proportion of respondents reported that window-opening behavior depends on the use of air conditioning (i.e., closing windows when air conditioning was used and opening them when it was not used).

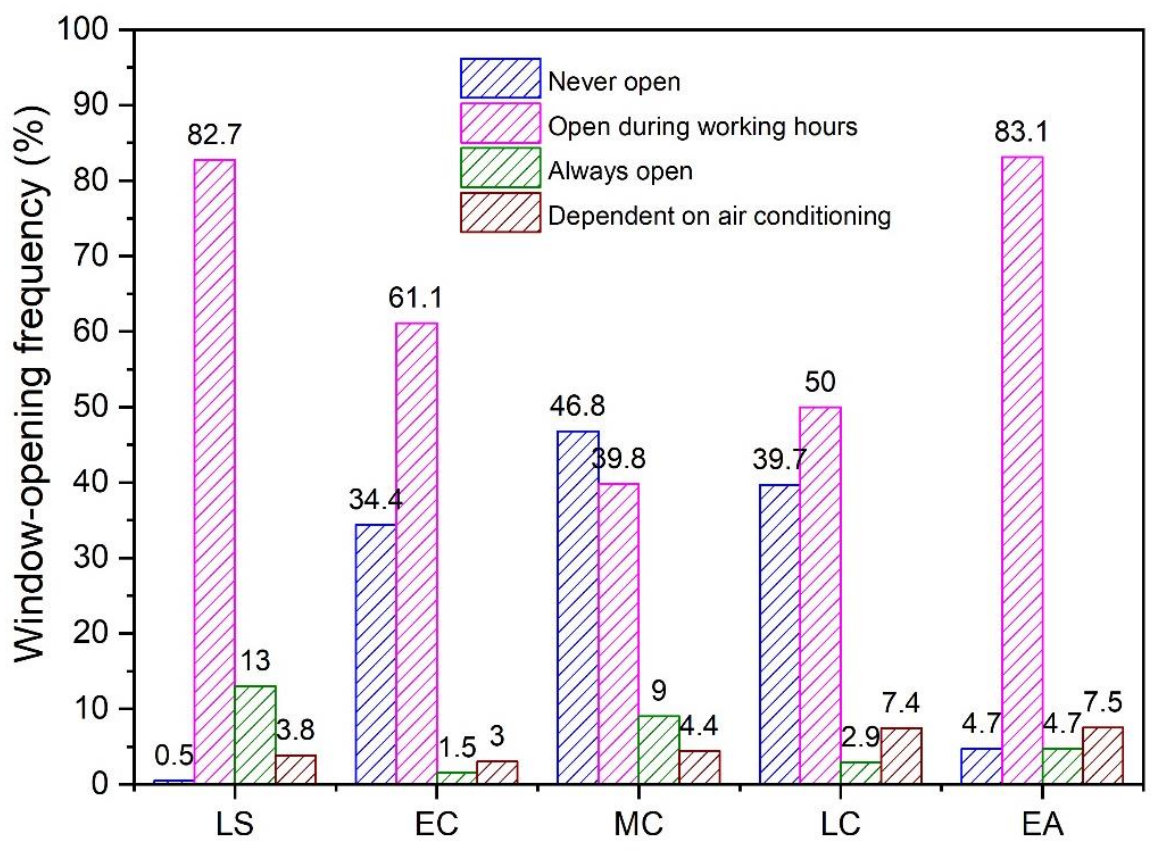


Fig. 13. Frequency of window adjustment during the five study periods.

In previous studies[8, 49-52], the indoor and outdoor temperature and relative humidity have been shown to be the dominant correlation factors with window-opening behavior. Pearson correlation analysis of the data, including the level of significance (p) obtained in this study was performed, as illustrated in Table 7. In general, a positive or negative relationship exists when $r>0.3$ or $r<-0.3$. In a recent work in northeastern China[26], it was demonstrated that window-opening was not affected by variations in temperature but by variations in relative humidity $(\mathrm{RH})$. In this research, the windowopening frequency showed good correlation with the indoor RH in LS, EC and LC, but the other environmental parameters were poorly correlated. In LS, it coincided with the 'meiyu' season (a period of constant rain) in the surveyed region. The indoor air temperature increased to some extent, and occupants regularly opened windows to relieve the feeling of tightness caused by high humidity. Therefore, there was a positive relationship between the proportion of window-opening and the indoor relative humidity. when air conditionings were used, the proportion of window-opening decreased in EC. However, from Fig.9 it can be observed that the indoor relative humidity increased, and resulted in a negative relationship with the proportion of window-opening.

In MC, the window-opening behavior showed significant correlation with the outdoor relative humidity. It can be observed in Fig. 13 that the occupants opened windows even in MC to let in fresh air. However, when the outdoor relative humidity increased continuously, occupants tended to close the windows, preventing the flow of wet outdoor air inside the building thereby maintaining thermal comfort levels.

\section{Table 7}

Correlation between factors influencing window-opening behavior in this study.

\begin{tabular}{|c|c|c|c|c|c|c|c|c|c|c|}
\hline \multirow{3}{*}{ Category } & \multicolumn{10}{|c|}{ Correlation analysis } \\
\hline & \multicolumn{2}{|c|}{ LS } & \multicolumn{2}{|c|}{$\mathrm{EC}$} & \multicolumn{2}{|c|}{$\mathrm{MC}$} & \multicolumn{2}{|c|}{$\mathrm{LC}$} & \multicolumn{2}{|c|}{ EA } \\
\hline & $\mathrm{r}$ & $\mathrm{p}$ & $\mathrm{r}$ & $\mathrm{p}$ & $\mathrm{r}$ & $\mathrm{p}$ & $\mathrm{r}$ & $\mathrm{p}$ & $\mathrm{r}$ & $\mathrm{p}$ \\
\hline $\begin{array}{c}\text { Indoor } \\
\text { temperature }\end{array}$ & 0.621 & 0.137 & -0.07 & 0.719 & -0.168 & 0.691 & -0.149 & 0.811 & 0.036 & 0.927 \\
\hline $\begin{array}{l}\text { Indoor relative } \\
\text { humidity }\end{array}$ & $0.624^{*}$ & 0.044 & $-0.917^{*}$ & 0.010 & -0.225 & 0.175 & $-0.411^{*}$ & 0.046 & -0.214 & 0.274 \\
\hline $\begin{array}{c}\text { Outdoor } \\
\text { temperature }\end{array}$ & 0.301 & 0.398 & $-0.668^{*}$ & 0.049 & -0.163 & 0.481 & 0.055 & 0.888 & -0.262 & 0.327 \\
\hline $\begin{array}{l}\text { Outdoor } \\
\text { relative } \\
\text { humidity }\end{array}$ & 0.152 & 0.656 & -0.173 & 0.682 & -0.347 & 0.246 & 0.046 & 0.913 & -0.136 & 0.691 \\
\hline
\end{tabular}




\subsubsection{Air-conditioning adjustment}

The frequency of air-conditioning adjustment is defined as the ratio of the number of rooms with air-conditioning to the total surveyed number of rooms at one environmental parameter bin. The airconditioning adjustment frequency relative to the outdoor air temperature in the five periods was shown in Fig. 14. In EA and LS, the air-conditioning opening frequency was nearly zero. In MC, the frequency was approximately 1 (representing $100 \%$ ), although the outdoor air temperature was $26^{\circ} \mathrm{C}$. In EC, the air-conditioning opening frequency, which varied in the range of 0.5 to 1 , had strong correlation with the outdoor air temperature, which varied in the range of $23^{\circ} \mathrm{C}$ to $30^{\circ} \mathrm{C}$. In $\mathrm{LC}$, the airconditioning opening frequency varied from 0.6 to 0.9 when the outdoor air temperature varied from $23^{\circ} \mathrm{C}$ to $32^{\circ} \mathrm{C}$.

Considering the growth dose representation, a best fit curve of the air-conditioning opening frequency with the outdoor air temperature was plotted (see Fig. 14). The air-conditioning opening frequency for the five periods in this study can be expressed as:

$$
P_{A C}=\frac{1}{1+e^{\left(t_{\text {out }}-26.5\right) d t_{\text {out }}}}
$$

where, $P_{A C}$ is the proportion of air-conditioning opening, and $t_{\text {out }}$ is the outdoor air temperature.

The pseudo $\mathrm{R}^{2}$ was 0.894 , which meant a good degree of fit.

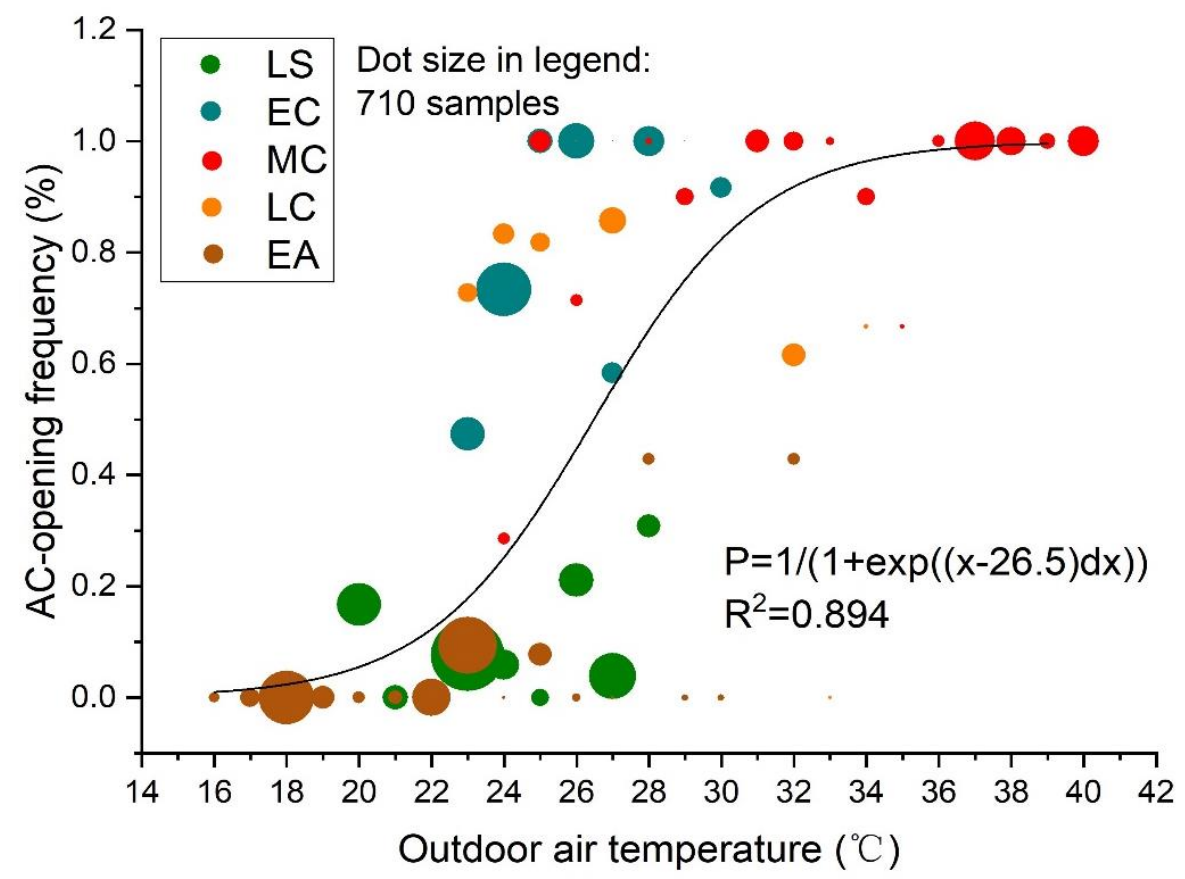

Fig. 14. Frequency of air-conditioning adjustment during the five study periods

When the indoor thermal environment is harsh, and the physical, psychological and behavioral adjustment cannot achieve human thermal comfort, active technology is needed. It should be noted that the air conditioning unit was operated far more during the cooling season than the particularly 
common in EC (63.4\% of the proportion) and LC (51.1\% of the proportion), whereas the temperature settings varied more in $\mathrm{MC}$, albeit $25^{\circ} \mathrm{C}$ still remained the most common set point.

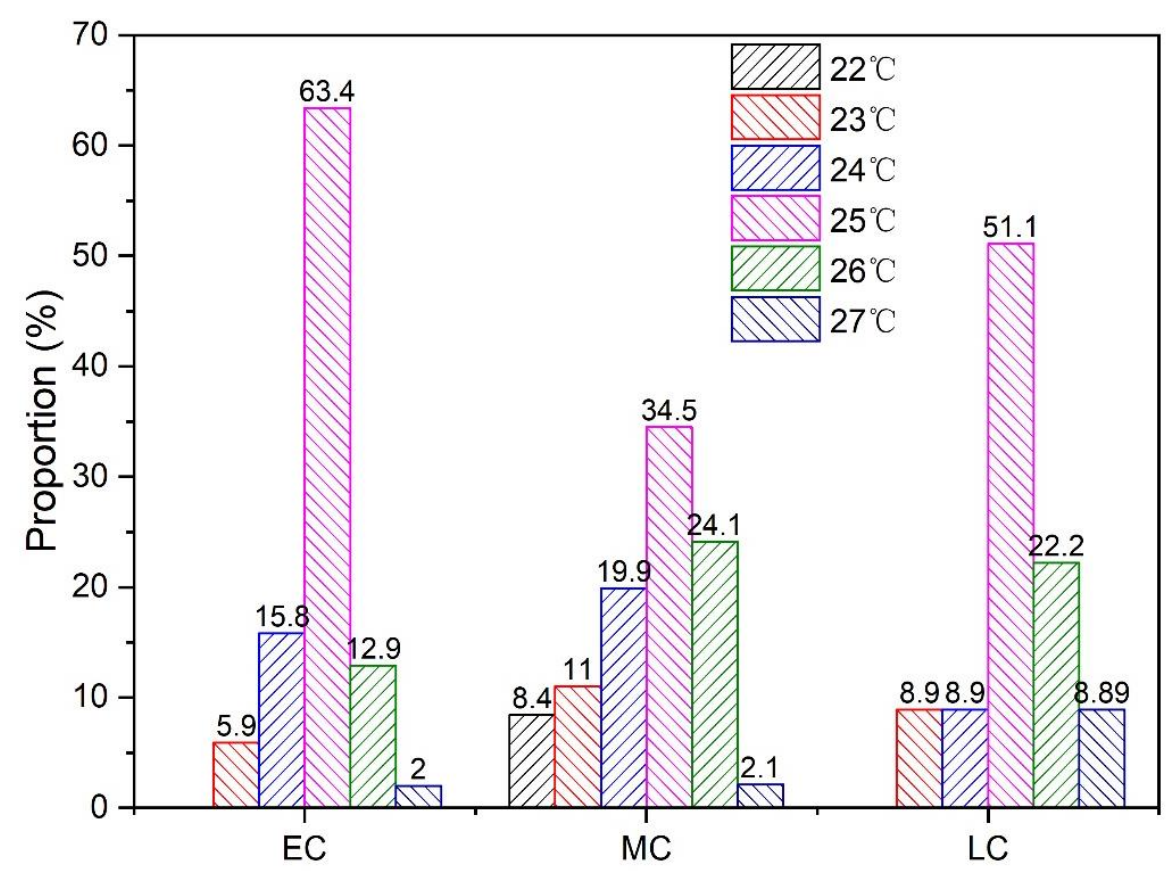

Fig. 15. Distribution of air-conditioning temperature setting during the three refrigeration operation periods.

\section{Discussion}

\subsection{Comfort temperature range of indoor environments}

The current comfort range adopted by ASHRAE indicates PMV values ranging from -0.5 to +0.5 that the $90 \%$ of the occupants would achieve thermally satisfied[36]. However, occupants' adaptability in a dynamic environment leads to a wider range of acceptable thermal comfort temperature[30, 53]. In this study, the acceptable and comfortable temperature ranges were calculated based on actual thermal sensation votes (TSV of -0.5 to +0.5 ). Using the formulas in Table 5 and setting TSV to -0.5 and 0.5 , the lower and upper comfortable temperature limits were calculated for the surveyed buildings. The calculations also included other conditions such as $\mathrm{RH}$ (set in the range of 50-70\%) and air velocity $(0.05-0.15 \mathrm{~m} / \mathrm{s})$ (Table 8$)$.

A comparison of the indoor comfortable temperature range in the Chinese standard [54]with the adaptive values calculated in this study shows that the latter deviated from the expected values, particularly in LS, LC, and EA. In LS and EA, the lower limit was less than the standard value, suggesting that during transition seasons people can feel comfortable in lower temperatures. In EC and LC, respondents could tolerate a higher air temperature before using air conditioning. In MC, the upper comfort limit was $29.6^{\circ} \mathrm{C}$, but respondents felt slightly cool when the air temperature was below $24.6{ }^{\circ} \mathrm{C}$. Overall, using the comfortable temperature range determined using our adaptive methods widens the interior comfort zone, thereby suggesting the potential for energy savings. 


\section{Table 8}

Comfortable interior temperature ranges for all periods calculated at 50-70\% indoor relative humidity and 0.05$0.15 \mathrm{~m} / \mathrm{s}$ wind speed.

\begin{tabular}{ccc}
\hline Period & Lower Limit $\left({ }^{\circ} \mathrm{C}\right)$ & Upper Limit $\left({ }^{\circ} \mathrm{C}\right)$ \\
\hline LS & 21.7 & 27.1 \\
EC & 23.6 & 27.8 \\
MC & 24.6 & 29.6 \\
LC & 22.0 & 29.4 \\
EA & 20.5 & 27.8 \\
\hline
\end{tabular}

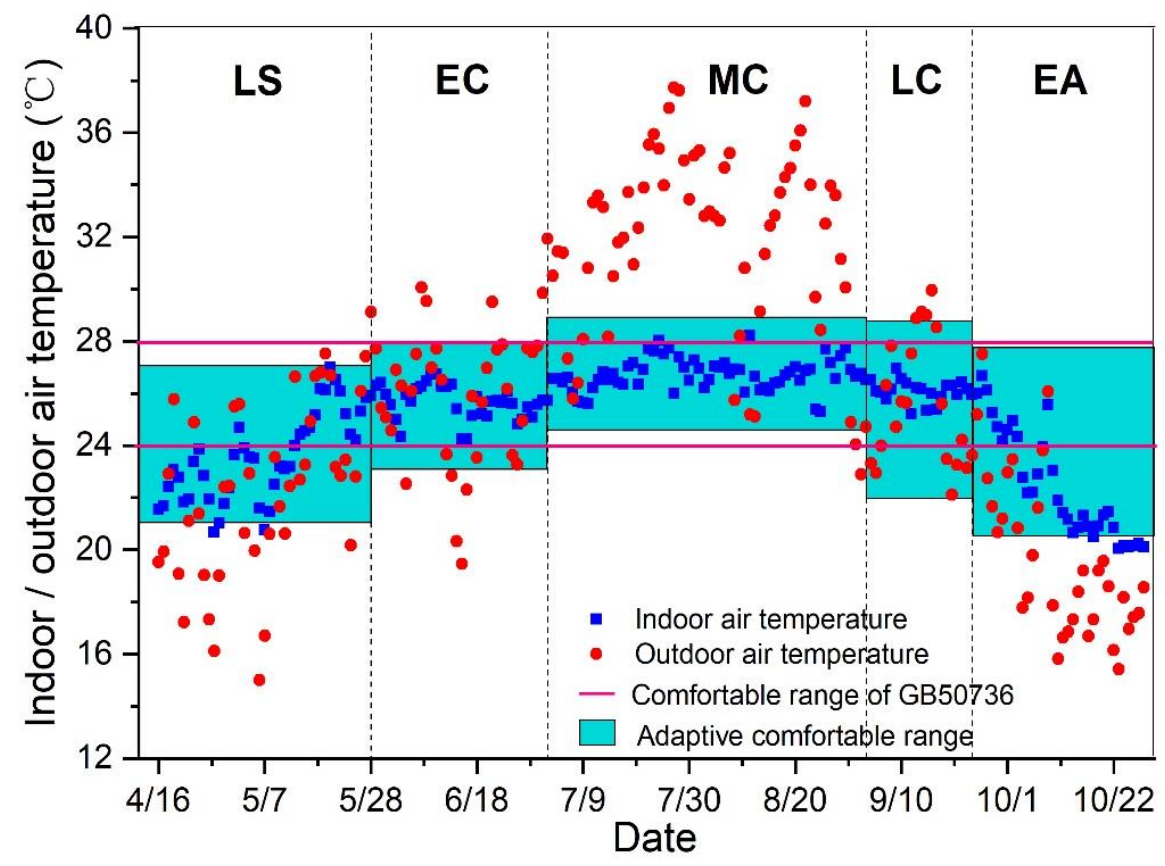

Fig. 16. Comparison of standard interior comfortable ranges set by the GB50736 (pink lines) and calculated in this study (blue shading).

According to the adaptive comfort theory[8], personal thermal sensations vary with season, and this can be attributed to behavioral, physiological, and psychological adjustments[17]. For instance, although the average clothing insulation was the same in both EC and LC, the comfort range varied (Fig. 16), indicating that the influence of different thermal histories on human physiological and psychological adaptations on temperature conditions. Variations in the indoor comfort temperature ranges between ER and LR can be ascribed to indoor thermal experiences as different indoor heating experiences can significantly affect occupants' thermal responses[25].

As shown in Fig. 16, the comfort temperature range varied more in LC than EC and the former had wilder limits, indicating that a lower temperature limit can occur for occupants exposed to a low indoor cooling temperature in MC. Meanwhile, having experienced lower indoor temperatures in MC, it is anticipated that occupants might develop a psychological expectation for lower temperatures in a later 
period.

The results in Fig.16 and subsequent discussions are supported by the fact that laboratory experiments have shown that physiological acclimatization processes operate in different ways in different seasons[55]. This is further illustrated with the following example; in summer the human body becomes more sensitive to cold environments developing an increased tolerance for higher temperatures. Therefore, behavioral, physiological, and psychological adjustments have a significant impact on thermal sensation, and variations in these adjustments lead to dynamic changes in the comfort temperature range.

\subsection{Energy saving potential of dynamic comfort ranges}

A better understanding of thermal tolerance and comfort range is necessary to quantify the energy saving potential and reduce energy consumption. For example, under both current and future climate scenarios, lowering the acceptability limits of thermal comfort criteria from $90 \%$ to $70 \%$ could affect energy consumption in Australia by over 40\% [56]. In the simulation of reference office buildings in the United States climate zones, it was demonstrated that the cooling energy saving potential can be increased by $29 \%$ by extending the temperature set-points from $22.2{ }^{\circ} \mathrm{C}$ to $25{ }^{\circ} \mathrm{C}$ [57]. However, the study examined the energy saving potential of increasing/decreasing the temperature set points in HVAC systems but lacked actual data of occupants' long- and short-term thermal adaptations and their thermal comfort levels at these set points. Thus, performance modelling should consider not only the impact of using technology and the energy performance of the building's envelope, but also the occupants' thermal comfort.

Considering the factors of local climate, culture and behaviors, the local design standards were more suitable for the study of Chinses occupants. In building performance simulation in China, the comfort boundary is set between $18{ }^{\circ} \mathrm{C}$ in winter and $26^{\circ} \mathrm{C}$ in summer accordance with the local design standards[54]. The dynamic comfort temperature range defined in this study for Chongqing (Fig. 16) can be used to set new values for higher energy saving potential. In order to quantify the energy potential, this study compared the energy consumption between the standard range and the dynamic comfort range using the simulation method.

The simulation model and boundary conditions of the free-running condition were presented in Table 2 and section 2.3. We applied these basic parameters and the time schedule of setting the airconditioning system (presented in Table 9) to simulate the energy consumption in each period.

\section{Table 9}

Time schedule of setting air-conditioning.

\begin{tabular}{ccc}
\hline Building type & Working days & Non-working days \\
\hline Office buildings & $8: 00-18: 00$ & - \\
\hline
\end{tabular}

Fig. 17 illustrated the comparison between the standard range and the dynamic comfort range in 
each period. Over the entire period, the former consumed $29.04 \mathrm{kWh} / \mathrm{m}^{2}$ whereas the latter consumed $19.07 \mathrm{kWh} / \mathrm{m}^{2}$, indicating overall energy savings of $34.33 \%$. The savings in each period were $18.73 \%$, $23.22 \%, 37.87 \%, 51.16 \%$, and $60.61 \%$, respectively.

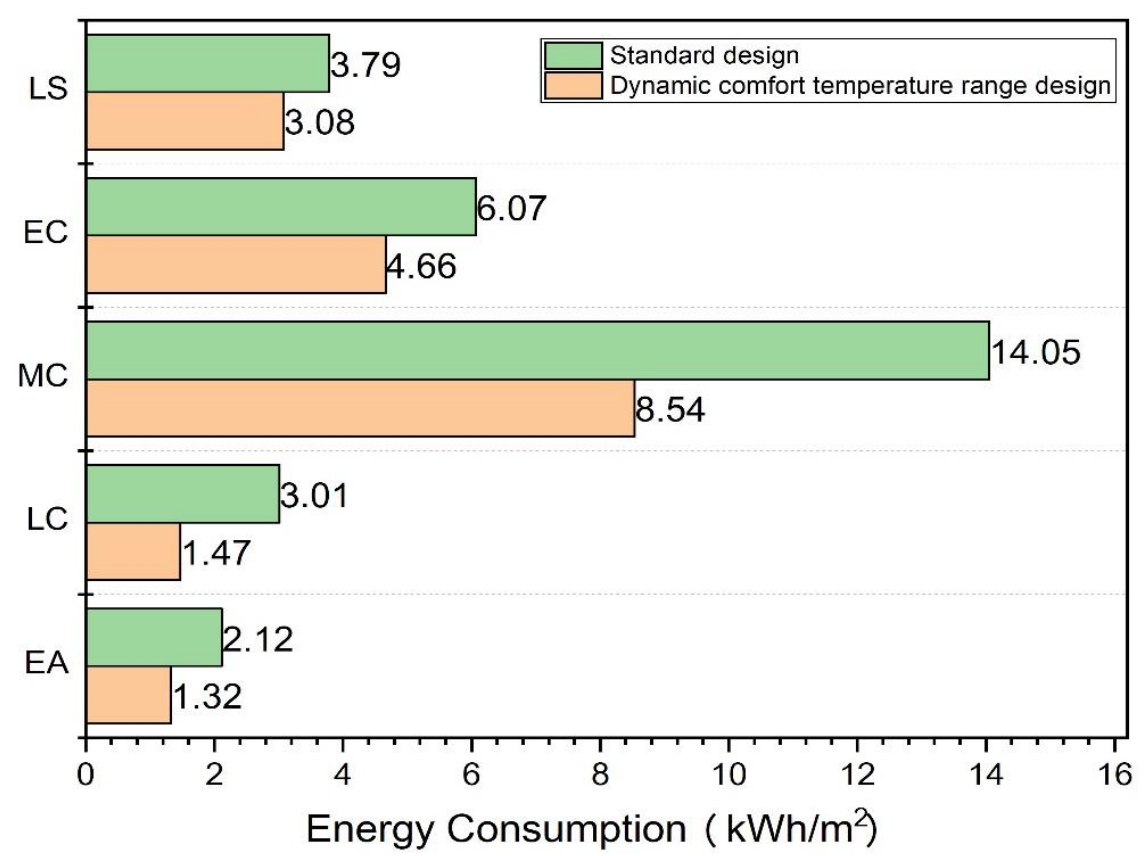

Fig. 17. Comparison of energy consumption between the standard design and dynamic comfort temperature range design by period.

Technological innovations and improvements have long been at the center of policy based approaches for improving building energy performance and reducing building energy use[58]. However, occupants' adaptability and personal behavior play more important roles in building energy conservation. This study demonstrated that the energy consumption in typical office buildings could be reduced by $34.33 \%$ by adopting the dynamic comfort temperature range design. Furthermore, we showed that occupants' adaptability and personal behavior can lead to significant energy savings. The research findings provide instructive reference for indoor air temperature design to enhance the potential of building energy conservation.

\section{Conclusions}

This study proposed a framework for a tracking method combined with online survey and remote measurement of indoor environmental parameters. The method can be used to conduct an in-depth occupancy behavior for thermal comfort research and identify the impact on energy consumption. The advantage of this method is its capability of capturing continuous fluctuations in the seasonal classified thermal environment and occupants' thermal sensation feedbacks. It fills the gap of limitations of traditional survey methods that only obtain static data at a certain time. The key findings of this study conducted in the three mixed-mode office buildings can be summarized as follows: 
1) The climate-characterized period has been classified into five periods based on the indoor thermal environment evaluation, named Latter Spring (LS), Early Cooling period (EC), Middle Cooling period (MC), Latter Cooling period (LC) and Early Autumn (EA). This will be very helpful to the building energy system flexibility design and operation.

2) The case study demonstrates that human adaptive behavior, including clothing insulation changes, window adjustments, and air conditioning use, has a fine seasonal sensitivity and individualdependent. In this study, it is revealed that occupants were more sensitive to the environmental changes in Early Autumn (EA) than in Late Spring (LS), as well as in Early Cooling (EC) than in Latter Cooling (LC). In addition, the window-opening probability was not driven by temperature changes but rather by relative humidity variations. Occupants were more sensitive to the environmental changes in Early Autumn (EA) than in Late Spring (LS), as well as in Early Cooling (EC) than in Latter Cooling (LC). Window opening behavior is also affected by humidity.

3) The existing design standard fixes the cooling period and setting point which can lead to energy wastage. It is evidenced that the occupant-demand oriented cooling system design and operation strategy can achieve energy saving. In this case study, the energy saving is estimated about $34.33 \%$. The division of five-season period can provide guidance to annual flexible energy operation. It is suggested the concept of dynamic comfort temperature range should be considered in evaluation of indoor thermal environment.

\section{Acknowledgements}

This work was supported by the National Key R\&D Program "Solutions to Heating and Cooling of Buildings in the Yangtze River Region (SSHCool) " [Grant No: 2016YFC0700301] and project supported by the Fundamental Research Funds for the Central Universities [Grant No: 2019CDXYCH0027] and [Grant No: 2018CDJDCH0015]. The author would like to thank the China Scholarship Council (CSC) for sponsoring a research visit abroad between 2018 and 2019, and also Dr. Du Chenqiu for her valuable comments. 


\section{Appendix A}

\section{Questionnaire for indoor thermal environment tracking survey}

1. Basic information of respondents:

Gender: $\square$ male $\square$ female

Age: $ـ$ Height: $\mathrm{cm}$; Weight: $\mathrm{kg}$

Lived in the current city for year(s)

Number of people in room:

2. Present dressing ( you can choose more than one for each item) :

Upper clothes: $\square$ T-shirt, $\square$ shirt, $\square$ a suit and tie, $\square$ thin coat, $\square$ none

Lower clothes: $\square$ trousers, $\square$ shorts, $\square$ dresses, $\square$ skirts

Shoes: $\square$ sneaker, $\square$ leather shoes, $\square$ sandals, $\square$ slipper

Socks: $\square$ socks (thin), $\square$ silk socks, $\square$ none

Others: $\square$ please specify:

3. Activities for respondents:

$\square$ reclining, $\square$ sitting, $\square$ standing, $\square$ walling

4. Feeling at present:

Temperature: $\square$ cold, $\square$ cool, $\square$ slightly cool, $\square$ neutral, $\square$ slightly warm, $\square$ warm, $\square$ hot

Humidity: $\square$ too dry, $\square$ dry, $\square$ slightly dry, $\square$ neutral, $\square$ slightly humid, $\square$ humid, $\square$ too humid

Air movement: $\square$ no air flow, $\square$ slightly air flow, $\square$ obvious air flow, strong air flow

5. Thermal sensation at present:

$\square$ Satisfied, $\square$ slightly satisfied, $\square$ acceptable, $\square$ slightly dissatisfied, dissatisfied

6. Thermal expectations at present:

Temperature: $\square$ lower, $\square$ maintained, $\square$ higher

Humidity: $\square$ lower, $\square$ maintained, $\square$ higher

Air movement: $\square$ weaker, $\square$ maintained, $\square$ stronger

7. The present status of air conditioners:

Opened (setting temperature:__,$\square$ closed 


\section{The present status of windows:}

$\square$ partially opened, $\square$ totally opened, $\square$ closed

\section{The habit of opening windows:}

never open, $\square$ open during working hours, $\square$ always open, $\square$ depended on air conditioning ( closed when the air conditioner turn on), $\square$ others:

\section{What measures did take to make yourself more comfortable?}

reduced clothes, $\square$ used the fan, $\square$ had a cold drink, $\square$ increased clothes, had a hot drink, $\square$ none, $\square$ others:

\section{References:}

[1] C. Chun, A. Kwok, T. Mitamura, N. Miwa, A. Tamura, Thermal diary: Connecting temperature history to indoor comfort, Building and Environment, 43 (5) (2008) 877-885.

[2] G. Walker, E. Shove, S. Brown, How does air conditioning become 'needed' ? A case study of routes, rationales and dynamics, Energy Research \& Social Science, 4 (2014) 1-9.

[3] W. Yu, B. Li, H. Jia, M. Zhang, D. Wang, Application of multi-objective genetic algorithm to optimize energy efficiency and thermal comfort in building design, Energy and Buildings, 88 (2015) 135-143.

[4] U. Berardi, A cross-country comparison of the building energy consumptions and their trends, Resources, Conservation and Recycling, 123 (2017) 230-241.

[5] Q. J. Kwong, N. M. Adam, B. B. Sahari, Thermal comfort assessment and potential for energy efficiency enhancement in modern tropical buildings: A review, Energy and Buildings, 68 (2014) 547557.

[6] W. 0'Brien, H. B. Gunay, The contextual factors contributing to occupants' adaptive comfort behaviors in offices - A review and proposed modeling framework, Building and Environment, 77 (2014) 77-87.

[7] F. Stazi, F. Naspi, M. D’ Orazio, A literature review on driving factors and contextual events influencing occupants' behaviours in buildings, Building and Environment, 118 (2017) 40-66.

[8] H. Liu, Y. Wu, B. Li, Y. Cheng, R. Yao, Seasonal variation of thermal sensations in residential buildings in the Hot Summer and Cold Winter zone of China, Energy and Buildings, 140 (2017) 9-18.

[9] E. Barbadilla-Martín, J. M. Salmerón Lissén, J. Guadix Martín, P. Aparicio-Ruiz, L. Brotas, Field study on adaptive thermal comfort in mixed mode office buildings in southwestern area of Spain, Building and Environment, 123 (2017) 163-175. 
[10] E. Barbadilla-Martín, J. Guadix Martín, J.M. Salmerón Lissén, J. Sánchez Ramos, S. Álvarez Domínguez, Assessment of thermal comfort and energy savings in a field study on adaptive comfort with application for mixed mode offices, Energy and Buildings, 167 (2018) 281-289.

[11] R.F. Rupp, R. de Dear, E. Ghisi, Field study of mixed-mode office buildings in Southern Brazil using an adaptive thermal comfort framework, Energy and Buildings, 158 (2018) 1475-1486.

[12] R.F. Rupp, J. Kim, R. de Dear, E. Ghisi, Associations of occupant demographics, thermal history and obesity variables with their thermal comfort in air-conditioned and mixed-mode ventilation office buildings, Building and Environment, 135 (2018) 1-9.

[13] R. De Vecchi, C. Candido, R. de Dear, R. Lamberts, Thermal comfort in office buildings: Findings from a field study in mixed-mode and fully-air conditioning environments under humid subtropical conditions, Building and Environment, 123 (2017) 672-683.

[14] M. Luo, B. Cao, J. Damiens, B. Lin, Y. Zhu, Evaluating thermal comfort in mixed-mode buildings: A field study in a subtropical climate, Building and Environment, 88 (2015) 46-54.

[15] S. Dhaka, J. Mathur, Quantification of thermal adaptation in air-conditioned buildings of composite climate, India, Building and Environment, 112 (2017) 296-307.

[16] R. de Dear, G.S. Brager, D. Cooper, Developing an adaptive model of thermal comfort and preference, in: Final Report ASHRAE RP-884, 1998.

[17] J.F. Nicol, M.A. Humphreys, Adaptive thermal comfort and sustainable thermal standards for buildings, Energy and Buildings, 34 (60) (2002) 563-572.

[18] B. Li, W. Yu, M. Liu, N. Li, Climatic Strategies of Indoor Thermal Environment for Residential Buildings in Yangtze River Region, China, Indoor and Built Environment, 20 (1) (2011) 101-111.

[19] Y. Zhang, J. Wang, H. Chen, J. Zhang, Q. Meng, Thermal comfort in naturally ventilated buildings in hot-humid area of China, Building and Environment, 45 (11) (2010) 2562-2570.

[20] X. J. Ye, Z.P. Zhou, Z.W. Lian, H.M. Liu, C.Z. Li, Y.M. Liu, Field study of a thermal environment and adaptive model in Shanghai, Indoor air, 16 (4) (2006) 320-326.

[21] K. J. McCartney, J.F. Nicol, Developing an adaptive control algorithm for Europe, Energy and Buildings, 34 (2002) 623-635.

[22] H. B. Rijal, P. Tuohy, M. A. Humphreys, J.F. Nicol, A. Samuel, J. Clarke, Using results from field surveys to predict the effect of open windows on thermal comfort and energy use in buildings, Energy and Buildings, 39 (7) (2007) 823-836.

[23] T. Goto, T. Mitamura, H. Yoshino, A. Tamura, E. Inomata, Long-term field survey on thermal adaptation in office buildings in Japan, Building and Environment, 42 (12) (2007) 3944-3954.

[24] J. Liu, R. Yao, J. Wang, B. Li, Occupants' behavioural adaptation in workplaces with noncentral heating and cooling systems, Applied Thermal Engineering, 35 (2012) 40-54.

[25] H. Ning, Z. Wang, Y. Ji, Thermal history and adaptation: Does a long-term indoor thermal exposure impact human thermal adaptability?, Applied Energy, 183 (2016) 22-30.

[26] C. Sun, R. Zhang, S. Sharples, Y. Han, H. Zhang, A longitudinal study of summertime occupant behaviour and thermal comfort in office buildings in northern China, Building and Environment, 143 (2018) 404-420.

[27] M. Luo, B. Cao, W. Ji, Q. Ouyang, B. Lin, Y. Zhu, The underlying linkage between personal control and thermal comfort: Psychological or physical effects?, Energy and Buildings, 111 (2016) $56-63$.

[28] M. Luo, B. Cao, X. Zhou, M. Li, J. Zhang, Q. Ouyang, Y. Zhu, Can personal control influence human thermal comfort? A field study in residential buildings in China in winter, Energy and 
Buildings, 72 (2014) 411-418.

[29] S. Jing, B. Li, R. Yao, Exploring the "black box" of thermal adaptation using information entropy, Building and Environment, 146 (2018) 166-176.

[30] B. Li, C. Du, R. Yao, W. Yu, V. Costanzo, Indoor thermal environments in Chinese residential buildings responding to the diversity of climates, Applied Thermal Engineering, 129 (2018) 693-708.

[31] R. F. Rupp, N. G. Vásquez, R. Lamberts, A review of human thermal comfort in the built environment, Energy and Buildings, 105 (2015) 178-205.

[32] A. K. Mishra, M. Ramgopal, Thermal comfort in undergraduate laboratories - A field study in Kharagpur, India, Building and Environment, 71 (2014) 223-232.

[33] E. A. Essah, R. Yao, A. Short, Assessing stack ventilation strategies in the continental climate of Beijing using CFD simulations, International Journal of Ventilation, 16 (1) (2016) 61-80.

[34] IS0 7730:2005, Ergonomics of the Thermal Environment - Analytical Determination and Interpretation of Thermal Comfort Using Calculation of the PMV and PPD Indices and Local Thermal Comfort Criteria, in, International Standardization Organization, Geneva, 2005.

[35] C. H. X. Wang, J. Ye, Discussion about field measurement Technology and methods on PMV in an ecological building, Build. Energy Environ, 2(26) (2007) 83-87 [in Chinese].

[36] ANSI/ASHRAE 55 Standard, Thermal Environmental Conditions for Human 0ccupancy, in, ASHRAE, Atlanta, 2017.

[37] Y. Zhang, Q. Meng, Field study on thermal comfort and adaptation in buildings with split aircinditioners in hot-humid area of China(1): Thermal environment and perceptions, HV\&AC, 40 (3) (2014) 83-88 [ in Chinese].

[38] Chinese Standard GB/T50785-2012, Evaluation standard for indoor thermalenvironments in civil buildings, in, China Academy of Building Research andChongqing University, 2012 [in Chinese].

[39] D. P. Wyon, Y. Zhang, Methodology for indoor environmental research, HV\&AC, 36 (5) (2006) 5154 [in Chinese].

[40] Chinese Standard JGJ67-2006, Design code for office building, in, Ministry of construction of the People's Republic of China, 2006 [in Chinese].

[41] ASHRAE. Guideline14-2014, Measurement of energy and demand savings, in, GA30329 : American Society of Heating, Refrigerating and Air-Conditioning Engineers, Atlanta, 2014.

[42] DIN EN 15251, Indoor environmental input parameters for design and assessment of energy performance of buildings addressing indoor air quality, thermal environment, lighting and acoustics, in, Brussels Technical Committee, 2005.

[43] H. Ning, Z. Wang, X. Zhang, Y. Ji, Adaptive thermal comfort in university dormitories in the severe cold area of China, Building and Environment, 99 (2016) 161-169.

[44] H. Liu, Y. Wu, D. Lei, B. Li, Gender differences in physiological and psychological responses to the thermal environment with varying clothing ensembles, Building and Environment, 141 (2018) $45-54$.

[45] M. A. Humphreys, J.F. Nicol, The validity of IS0-PMV for predicting comfort votes in every-day thermal environments, Energy and Buildings, 34 (2002) 667-684.

[46] R. Yao, B. Li, J. Liu, A theoretical adaptive model of thermal comfort - Adaptive Predicted Mean Vote (aPMV), Building and Environment, 44 (10) (2009) 2089-2096.

[47] M. K. Singh, S. Mahapatra, S. K. Atreya, Adaptive thermal comfort model for different climatic zones of North-East India, Applied Energy, 88 (7) (2011) 2420-2428.

[48] W. Liu, Y. Zheng, Q. Deng, L. Yang, Human thermal adaptive behaviour in naturally ventilated 
offices for different outdoor air temperatures: A case study in Changsha China, Building and Environment, 50 (2012) 76-89.

[49] T. Ben-David, M. S. Waring, Impact of natural versus mechanical ventilation on simulated indoor air quality and energy consumption in offices in fourteen U.S. cities, Building and Environment, 104 (2016) 320-336.

[50] S. Pan, Y. Xiong, Y. Han, X. Zhang, L. Xia, S. Wei, J. Wu, M. Han, A study on influential factors of occupant window-opening behavior in an office building in China, Building and Environment, 133 (2018) 41-50.

[51] X. Zhou, T. Liu, X. Shi, X. Jin, Case study of window operating behavior patterns in an openplan office in the summer, Energy and Buildings, 165 (2018) 15-24.

[52] F. Haldi, D. Robinson, Interactions with window openings by office occupants, Building and Environment, 44 (12) (2009) 2378-2395.

[53] W. Yu, B. Li, R. Yao, D. Wang, K. Li, A study of thermal comfort in residential buildings on the Tibetan Plateau, China, Building and Environment, 119 (2017) 71-86.

[54] Chinses Standaed GB50736-2012, Design Code for Heating Ventilation and Air Conditioning of Civil Buildings, in, China Architecture \& Building Press, Beijing, 2012 [in Chinese].

[55] N. Umemiya, Seasonal Variations of Physiological Characteristics and Thermal Sensation under Identical Thermal Conditions, Journal of PHYSIOLOGICAL ANTHROPOLOGY, 25 (1) (2006) 29-39.

[56] Z. Ren, D. Chen, Modelling study of the impact of thermal comfort criteria on housing energy use in Australia, Applied Energy, 210 (2018) 152-166.

[57] T. Hoyt, E. Arens, H. Zhang, Extending air temperature setpoints: Simulated energy savings and design considerations for new and retrofit buildings, Building and Environment, 88 (2015) 8996.

[58] Y. Zhang, X. Bai, F. P. Mills, J.C.V. Pezzey, Rethinking the role of occupant behavior in building energy performance: A review, Energy and Buildings, 172 (2018) 279-294. 